\title{
MACRO DESIGN, STRUCTURE, AND MECHANICS OF THE LEFT VENTRICLE
}

Henry M. Spotnitz, MD*

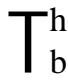
he functional anatomy of the left ventricle (LV) has been defined by anatomic dissection, ${ }^{1}$ light ${ }^{2,3}$ and electron microscopy, ${ }^{4,5} \mathrm{x}$-ray contrast angiography, ${ }^{6,7}$ two-dimensional echocardiography, ${ }^{8,9}$ nuclear magnetic resonance (NMR) tagging, ${ }^{10,11}$ implanted radiopaque markers, ${ }^{12,13}$ sonomicrometry, ${ }^{11,14,15}$ and other methods. ${ }^{16,17}$ Early in the history of cardiac surgery, interest in functional anatomy was spurred by inconsistent results of valve replacement ${ }^{18-20}$ and ventricular aneurysm surgery and by issues in correction of congenital heart disease. Although some inconsistency could be attributed to problems with myocardial protection or technical errors, other problems appeared to reflect incomplete understanding of $\mathrm{LV}$ functional anatomy. The importance of papillary muscle function in mitral valve surgery ${ }^{21-26}$ and of ventricular size and shape in LV aneurysmectomy ${ }^{27,28}$ have been emphasized in subsequent studies.

Maturation of intraoperative two-dimensional echocardiography further focused surgical interest in acute changes in function. The marked, intraoperative decrease in LV ejection fraction after valve replacement for chronic mitral regurgitation ${ }^{29}$ spurred study of valve repair and chordal preservation. ${ }^{21-26}$ Improving surgical materials, skill, and knowledge have made novel procedures like cardiomyoplasty, ${ }^{30} \mathrm{LV}$ volume reduction, ${ }^{31,32}$ and patch ventriculoplasty ${ }^{27}$ feasible, but they also challenge surgical investigators to define related changes in global and regional function.

From Department of Surgery, Columbia University College of Physicians and Surgeons, New York, NY.

This work was supported in part by US Public Health Service grant HL-48109.

Received for publication Dec 2, 1999; accepted for publication Jan $11,2000$.

Address for reprints: Henry M. Spotnitz, MD, Department of Surgery, Columbia University College of Physicians and Surgeons, 630 West 168th St, New York, NY 10032.

${ }^{*}$ George H. Humphreys, II, Professor of Surgery.

J Thorac Cardiovasc Surg 2000;119:1053-77

Copyright (C) 2000 by The American Association for Thoracic Surgery

$0022-5223 / 2000 \$ 12.00+0 \quad \mathbf{1 2 / 1 / 1 0 5 6 5 4}$

doi: $10.1067 / \mathrm{mtc} .2000 .105654$
Physiologic understanding of LV function can facilitate definition of the appropriate role for new procedures and help explain successes and failures. Thus enthusiasm for LV volume reduction has waxed and waned rapidly with little understanding of why the operation succeeded in some patients and failed in others, leaving uncertainty about who is an appropriate candidate for such surgery. Looking ahead, advances in surgical capacity to remodel and rearrange ventricular anatomy and an avalanche of new tools, including skeletal muscle grafts, mechanical assist devices, maze operations, pacing therapies for heart failure, and molecular and laser approaches to myocardial revascularization, will challenge our ability to understand new surgical tools and define their appropriate clinical role. The ability to meet this challenge begins with functional cardiac anatomy.

This review summarizes current understanding of the relation between structure and function of the LV. Some areas in which such knowledge is incomplete and analytic methods are flawed are discussed. Illustration of how current understanding may contribute to further progress in clinical surgery is an underlying goal.

\section{Technical issues}

The heart has been described as "a complex threedimensional and fiber-wound structure with mechanical properties that are nonlinear, anisotropic, time varying, and probably spatially inhomogeneous." 33 The LV, the heart's most structurally complex region, has proven remarkably resistant to analysis of functional anatomy. Studies have generally been based on quantitative histology or dynamic measurements. Quantitative histology requires fixed tissue that accurately reflects conditions in vivo. Proper relation of sample dimensions to three-dimensional LV architecture is also essential. Dynamic studies are compromised by difficulty defining the location of the endocardial surface when that surface buckles and thickens during systole. When resolution is coarse, as in echocardiography, dynamic techniques provide measurements averaged over a slice several millimeters thick. Such data are not directly comparable with histologic sections, which are a frac- 

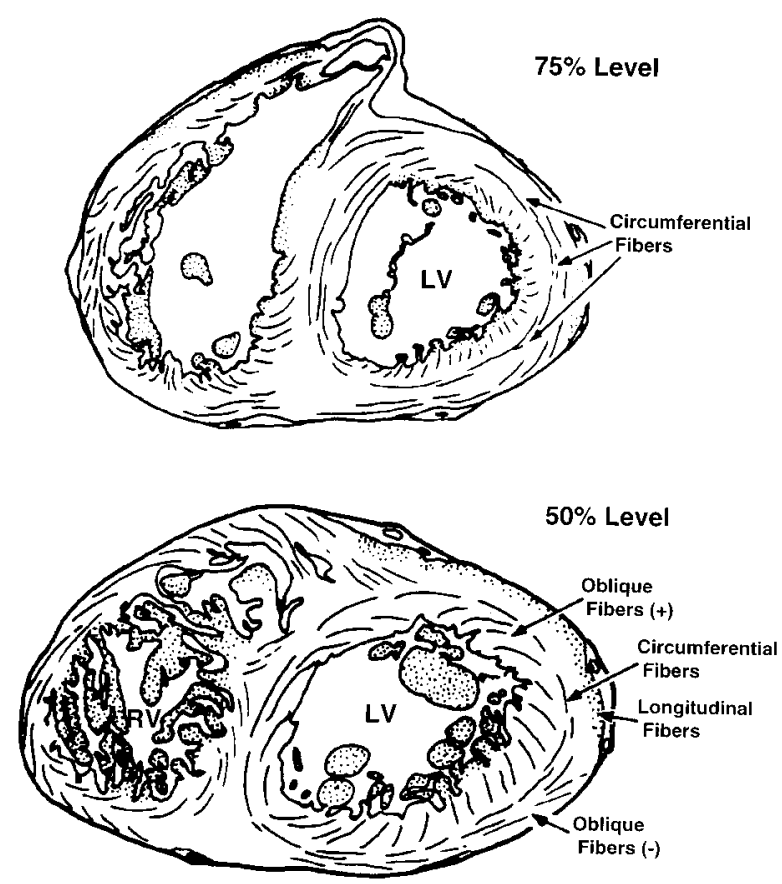

Fig 1. Cross sections of the human heart at the tip of the mitral valve $(75 \%$ level) and mid ventricle (50\% level). Roughly circular geometry of LV, variable fiber orientation, and irregularities of wall related to papillary muscles and trabeculae are apparent. (Modified from Greenbaum RA, Ho SY, Gibson DG, Becker AE, Anderson RH. Left ventricular fibre architecture in man. Br Heart J 1981;45:248-63. Reproduced with permission from BMJ Publishing Group.)

tion of a millimeter in thickness. Markers or gauges that are implanted on a short-term basis may not move properly with surrounding tissues, and long-term implantation results in scarring that can cause tethering artifacts. Both dynamic and static techniques are troubled by complex movement of muscle bundles in three dimensions, which are difficult to envision and measure with two-dimensional techniques. The sum of all these difficulties is uncertainty about critical measurements like LV wall thickness, reported to increase from $20 \%$ to $80 \%{ }^{6}$ during normal systole. One recent study comparing NMR tagging and sonomicrometry reported values between $21 \%$ and $43 \%$ for LV wall thickening. ${ }^{11}$ Given these difficulties, there is a subjective element to selection of material in this review, favoring a unified view of LV functional anatomy, governed by the same rules of solid geometry that apply to other common three-dimensional structures.

\section{Ventricular geometry and definitions}

The geometry of the normal LV resembles an ellipsoid of revolution (Figs 1-8), ${ }^{6,7,9,14-16}$ with its long axis

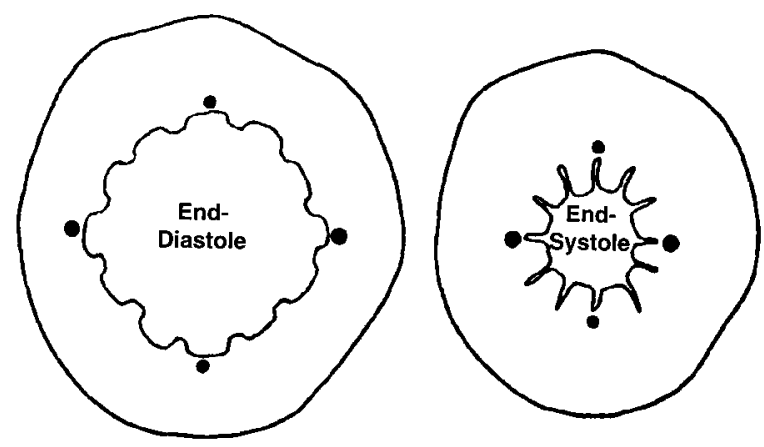

Fig 2. Schematic drawings summarizing angiographic studies of short-axis cross sections from the dog in systole and diastole. Geometry is roughly circular. Normal ejection fraction is associated with systolic wall thickening of $40 \%$ to $50 \%$. Exaggerated infolding of the innermost regions of the wall is apparent. Endocardial markers (black circles) are displaced from the inner boundary of the LV in systole by infolding. (Modified from Mitchell JH, Wildenthal K, Mullins CB. Geometric studies of the left ventricle utilizing biplane cinefluorography. Fed Proc 1969;28:1334-43. Reprinted with permission of the Federation of the American Society for Experimental Biology.)

directed from apex to base (Figs 4-7). Short-axis cross sections, perpendicular to the long axis, reveal circular geometry (Figs 1-5). Sections parallel to the long axis (meridional sections) reveal roughly ellipsoidal geometry (Figs 4-8). This concept ignores the presence of the right ventricle, atria, valves, aorta, papillary muscle, trabeculae carneae, and coronary vessels.

In the idealized ellipsoid, cross sections are circular, with uniform wall thickness (Figs 3 and 4) ${ }^{34}$ In the real LV, particularly at end-systole, the endocardial surface is irregular (Figs 1-3 and 6) relative to the epicardial surface, including the origin of papillary muscles and trabeculae..$^{1,6,7-9}$ There are important variations in both endocardial radius of curvature and wall thickness (Fig 8). Radius (r) and wall thickness (h) appear related, wall thickness being smallest at the apex (Fig 8), where the radius of curvature is also smallest. Mathematically, the relation of radius to wall thickness, $\mathrm{r} / \mathrm{h}$, is a determinant of the relation between pressure and afterload, ${ }^{7,18,19,35,36}$ as discussed below.

During systole, the ventricle shortens, narrows, twists, and thickens. ${ }^{6-17,37}$ Dimensions within the curved surface of the wall change in three principal directions, defined by polar coordinates. ${ }^{36}$ The wall thickens radially, in the direction of radii from the long axis to the epicardial surface. Apex to base shortening occurs along meridians, curved lines parallel to the long axis. Shortening around the waist of the ven- 

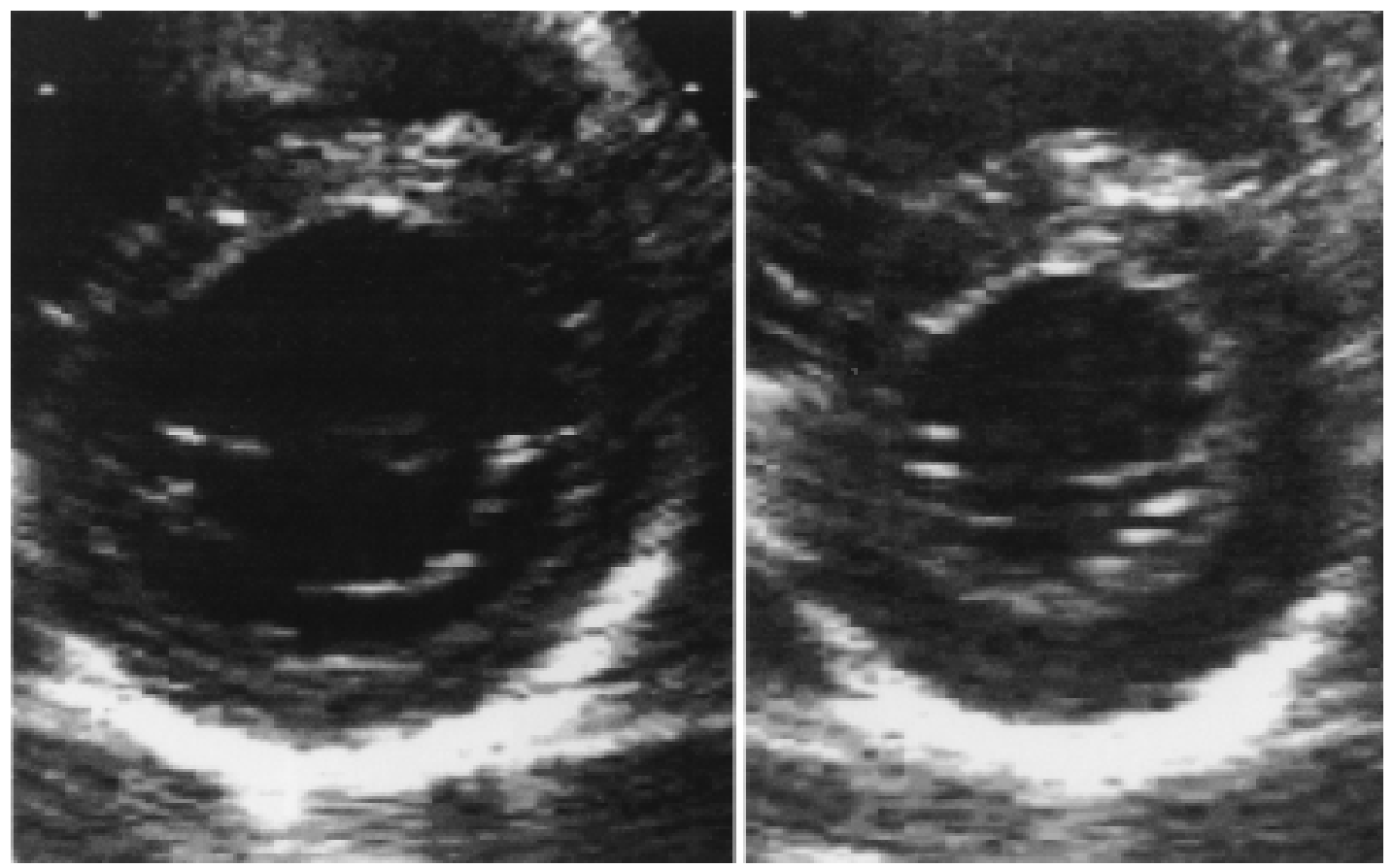

Fig 3. Short-axis two-dimensional echocardiograms of normal human LV. Ventricle appears roughly circular, with uniform wall thickness. Normal ejection fraction in these sections is associated with systolic wall thickening of $40 \%$ to $50 \%$. (Cabreriza SE, Spotnitz HM, unpublished data.)

tricle occurs circumferentially, along curved lines in the short-axis plane.

The apex twists relative to the base during systole, and metrics for torsion have been defined (Fig 5). 10,12,13 Measurement/definition of torsion, cleavage plane angles, and myocardial fiber angle are discussed below.

LV structure. The LV wall is composed predominantly of muscle fibers, also containing connective tissue, fat, arteries, veins, nerves, and lymphatics. ${ }^{38}$ The general organization of the muscle fibers resembles a ball of twine in a bath of fluid contained by the epicardium and endocardium. ${ }^{1,2}$ The fibers are relatively taut in the midwall and epicardial regions and more loosely wound in the endocardial regions, where inward buckling occurs in systole (Fig 2). ${ }^{6}$

Coronary arteries and veins course along the epicardial surface; penetrating vessels run perpendicular to the epicardium and carry the blood supply to the deeper layers. Myocardial capillaries run predominantly parallel to the long axis of the myocytes. ${ }^{39}$ Vessels connecting myocardial capillaries to the epicardial arteries and veins pass through many muscle layers and are subject to shearing forces during the cardiac cycle. The shear stresses produce discontinuities of flow and increase resistance during systole.
Ultrastructure. Myocardial fibers are composed of cells, elongated structures with central nuclei and branching attachments (Figs 9-11) that allow serial connections to one or more adjacent cells. ${ }^{4,5,38,40}$ The cells are composed predominantly of actin and myosin myofilaments organized into sarcomeres, with an alternating pattern of I bands and A bands (Fig 10).,5 Sarcomeres, bounded by $\mathrm{Z}$ lines, are stacked end to end to form myofibrils, which resemble cables and run parallel to the long axis of the myocyte (Fig 9). ${ }^{38}$ Contraction is triggered by calcium entry into the sarcoplasmic reticulum, which induces actin-myosin interaction, adenosine triphosphate hydrolysis, and release of energy. ${ }^{41} \mathrm{~A}$ change in the angle of myosin cross-bridges results in movement of actin and sarcomere shortening, which in turn shortens the length of the cell. ${ }^{41,42}$

In the transverse direction, across the shorter dimensions of the myocyte, the myofilaments are arranged in a precise, repetitive hexagonal array defined by stearic requirements for myosin cross-bridges to interact with active sites on the actin filaments. ${ }^{43}$ The cardiac myocyte is believed capable of active contraction only in the direction of the long axis. Dimension changes perpendicular to the long axis of the cell must be pas- 


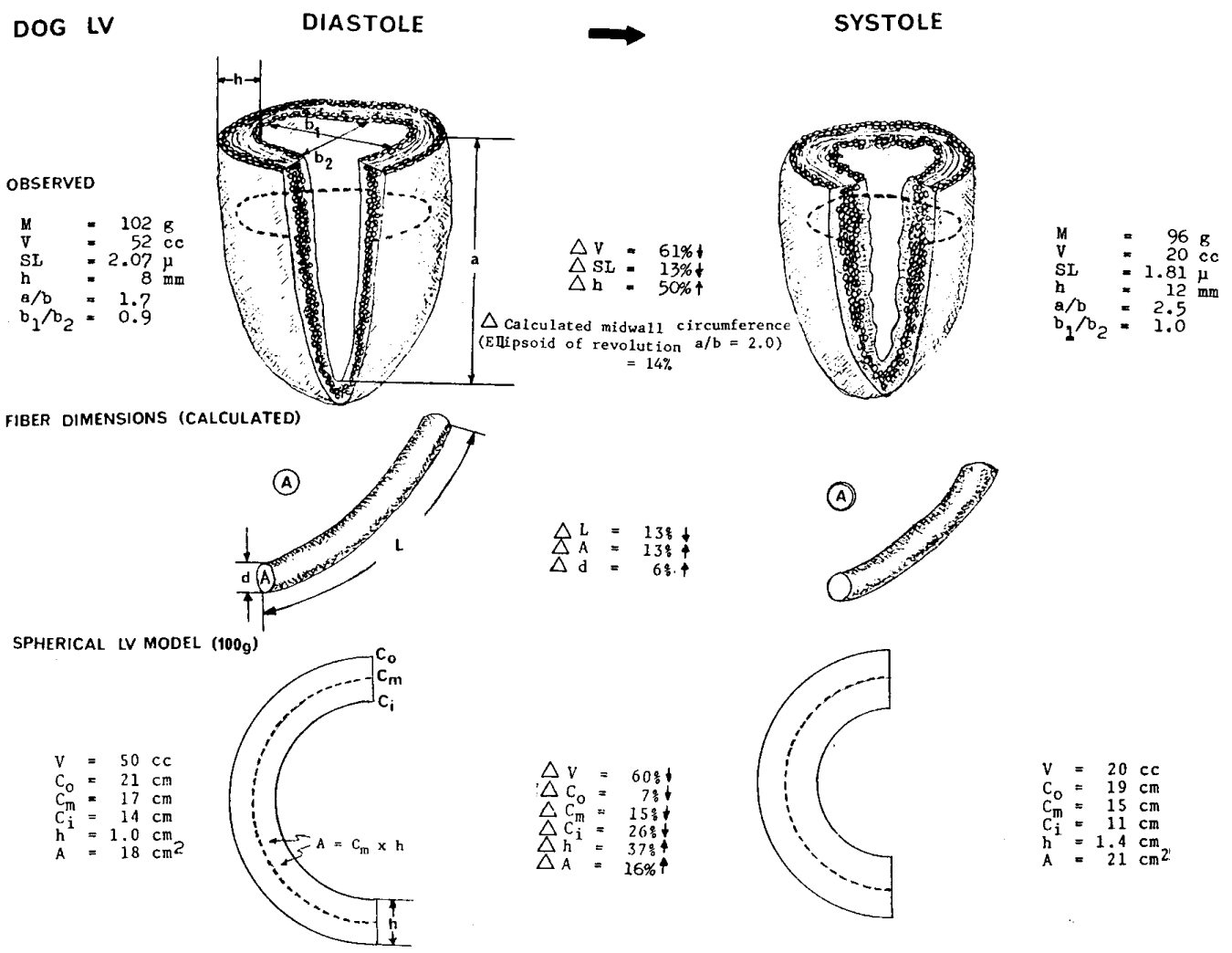

Fig 4. Upper panel illustrates dimensions of dog LVs weighing roughly $100 \mathrm{~g}$ fixed in diastole (left) and systole (right). Systole is associated with a 13\% decrease in sarcomere length $(S L)$, a $61 \%$ decrease in fixation volume from 52 to $20 \mathrm{~mL}(\mathrm{~V})$, and a $50 \%$ increase in wall thickness $(h)$. Middle panel illustrates hypothesized changes in fiber dimensions, including a $13 \%$ decrease in fiber length and a compensatory $13 \%$ increase in the cross-sectional area of the fiber (to keep fiber volume constant). A 13\% increase in cross section implies a 6\% increase in fiber thickness by the geometry of a circle. The lower panel illustrates dimensions calculated for a spherical model with volume and mass similar to the fixed ventricles. The $37 \%$ increase in calculated wall thickness of the model and the $15 \%$ decrease in midwall circumference $(\mathrm{Cm})$ are similar to measurements in the fixed ventricles. (Spotnitz HM, Sonnenblick EH. Structural conditions in the hypertrophied and failing heart. In: Mason DT, editor. Congestive heart failure. New York: Yorke Medical Books; 1976. p. 13-24.)

sive in nature or, alternatively, must reflect energy stored in elastic elements. ${ }^{38,44}$

Mitochondria are also prominent in cardiac cells and are more abundant in cardiac myocytes than in skeletal muscle myocytes (Fig 10). Mitochondria are factories for adenosine phosphorylation. Glycogen particles, an important substrate for anaerobic metabolism, and tubules of the sarcoplasmic reticulum providing calcium transport are visible in high-resolution electron micrographs. ${ }^{45}$ Synthesis of myofilaments and synthesis of sarcomeres can also be seen in appropriately selected tissue. ${ }^{45}$

The extracellular matrix of the myocardium has a complex and extensive structure of its own, consisting of intricate networks of noncontractile filaments orient- ed both transversely and parallel to the long axis of cardiac myocytes (Fig 11). Changes in this matrix have been described in LV hypertrophy and failure. ${ }^{38}$

Although a great deal is known about the ultrastructure of the myocardium, many issues are incompletely understood, and many structural elements that are believed to exist on the basis of experimental evidence from other sources remain to be defined. Thus the classic Hill model of the contractile element requires parallel elastic components that produce force during diastole and series elastic components that stretch during isovolumic systole. ${ }^{46}$ The concept of "myocardial slippage" or "creep" during chronic volume overload, infarction, or stunning requires relaxation of elements of the ventricular wall. ${ }^{47,48}$ Also, it is extremely diffi- 


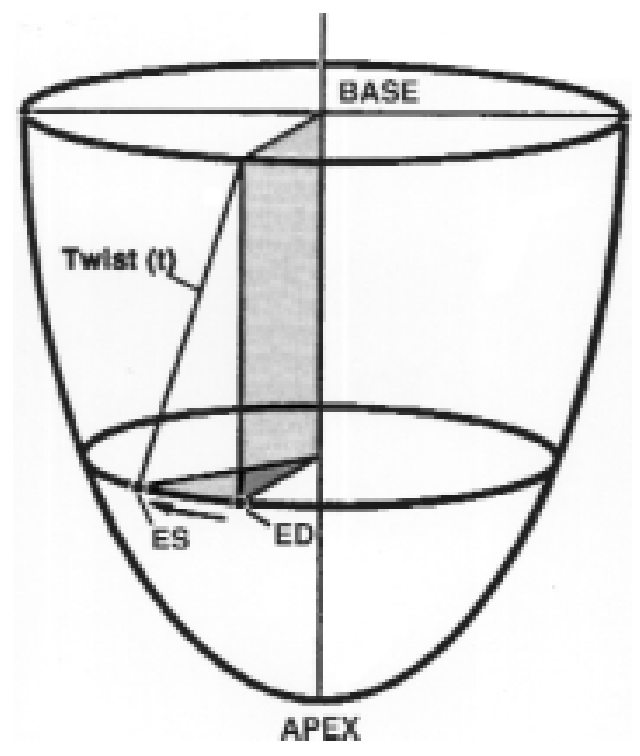

Fig 5. Ellipsoidal model defines measurement of systolic apical torsion of LV. Torsion displaces the marked point from $E D$ at end-diastole to $E S$ at end-systole. (Modified from Yun KL, Niczyporuk MA, Daughters GT 2d, Ingels NB Jr, Stinson EB, Alderman EL, et al. Alterations in left ventricular diastolic twist mechanics during acute human cardiac allograft rejection. Circulation 1991;83:962-73.)

cult to stretch myocardial sarcomeres beyond $2.3 \mu \mathrm{m},{ }^{4}$ whereas this is easily achieved in skeletal muscle. The structural correlate of this resistance to stretch is undefined. ${ }^{44}$ Finally, the remarkable uniformity of sarcomere length along and across the individual myocyte, as well as in adjacent myocytes (Figs 9 and 10), implies the presence of elastic elements that are not visible in standard electron micrographs. Many of these functions presumably are provided by collagen elastin and other elements of the extracellular matrix (Fig 11). ${ }^{38,44}$ Titin filaments, which connect $\mathrm{Z}$ lines to $\mathrm{M}$ bands, may prove important sources of diastolic forces and structural stability of the sarcomere. ${ }^{44}$

\section{Sarcomere length during the cardiac cycle}

Myosin filaments that form the dark A band in the center of the sarcomere are $1.5-\mu \mathrm{m}$ long and are not believed to shorten appreciably during systole. The maximum functional length of the myocardial sarcomere under physiologic stretch is about $2.25 \mu \mathrm{m}$, and the minimum length allowed by the myosin filaments is about $1.5 \mu \mathrm{m} ., 5,41$ All cardiac function is therefore based on an engine with an effective shortening capacity of only $0.75 / 2.25$ or $33 \%$. In reality, $10 \%$ to $20 \%$ sarcomere shortening appears to power the heart under all but the most extreme conditions. The sliding fila-

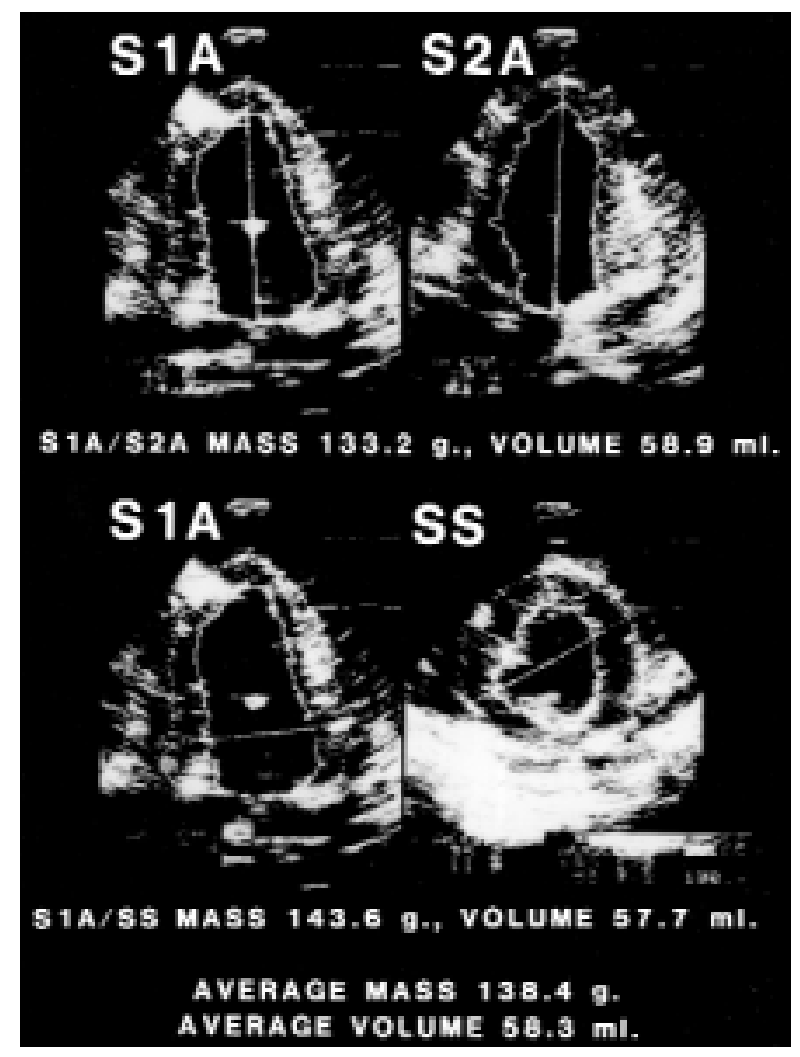

Fig 6. Two-dimensional echocardiograms of canine LV in long-axis ( $S 1 A$ and $S 2 A)$ and short-axis $(S S)$ sections. Varying radii of curvature and wall thickness compared with idealized models are apparent. (From Haasler GB, Rodigas PC, Collins RH, Wei J, Meyer FJ, Spotnitz AJ, et al. Two-dimensional echocardiography in dogs: variation of left ventricular mass, geometry, volume, and ejection fraction on cardiopulmonary bypass. J Thorac Cardiovasc Surg 1985;90:430-40. Reprinted with permission of Mosby, Inc.)

ment hypothesis of striated muscle suggests that optimum preload for force generation is 2.0 to $2.2 \mu \mathrm{m}$ and has been most elegantly supported experimentally in isolated skeletal muscle. In the dog heart, a midwall sarcomere length of $2.2 \mu \mathrm{m}$ corresponds to a fixation pressure of $10 \mathrm{~mm} \mathrm{Hg}$ (Fig 12).

Sarcomere lengths in cardiac tissue have been measured by quantitative electron microscopy, by light or laser diffraction techniques, and by optical magnification. ${ }^{4,5,45,47-53}$ Diffraction studies require muscle samples in which sarcomeres lie in register across the sample, as in papillary muscles and trabeculae. Quantitative electron microscopy requires carefully fixed tissue and meticulous sectioning of carefully oriented blocks. In dog hearts fixed to represent conditions of normal diastole, sarcomere length is most reproducible at midwall and can be 


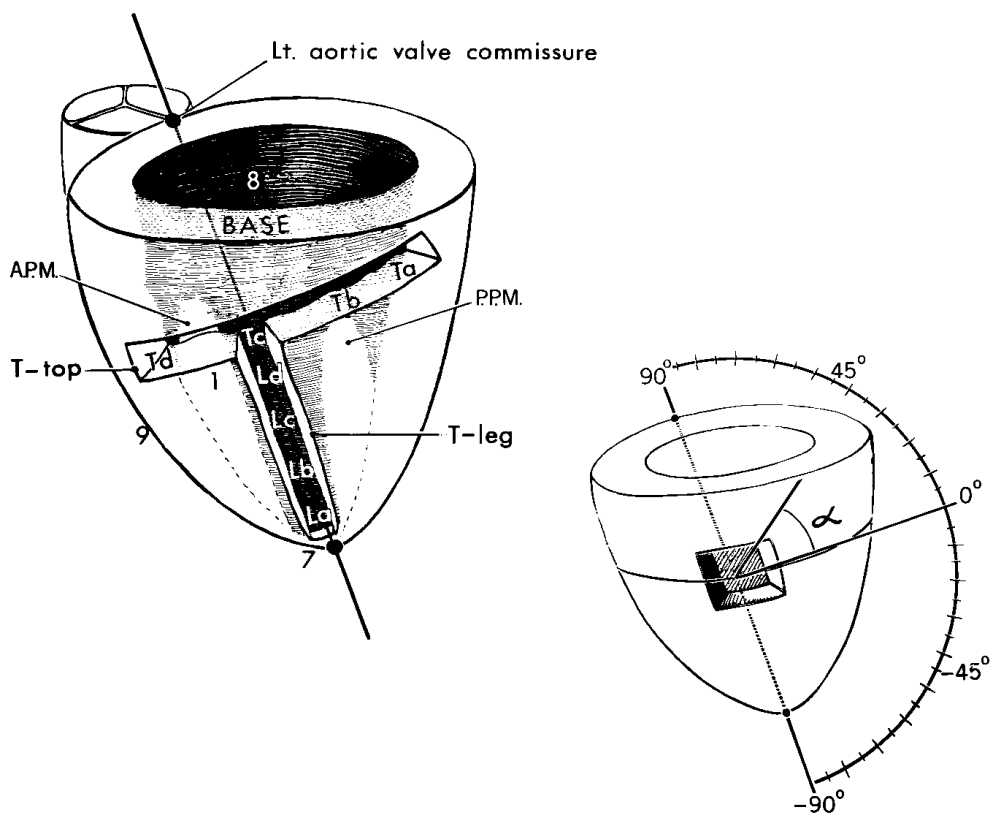

Fig 7. Definition of LV myocardial fiber orientation for fixed hearts containing silicone rubber casts. A metal pin was inserted in the long-axis orientation shown. The heart was mounted in an anvil with a knife guide that produced circular cuts coincident with the circumferential $\left(0^{\circ}\right)$ plane. A microscope with a rotating stage was used to estimate mean fiber orientation relative to $0^{\circ}$. Fibers with an angle of $60^{\circ}$ run obliquely upward to the right. Fibers with an angle of $-60^{\circ}$ run obliquely downward to the right. $A P M$, Anterior papillary muscle; $P P M$, posterior papillary muscle.

related to fixation pressure (Fig 12). ${ }^{4}$ Changes in sarcomere length with filling volume are qualitatively smallest in the epicardial third of the wall, intermediate at midwall, and largest at the endocardial surface (Fig 13). Average LV midwall sarcomere length in hearts fixed by coronary perfusion during systole is $1.81 \mu \mathrm{m}$ and 2.07 $\mu \mathrm{m}$ in hearts fixed to replicate diastole (Figs 4 and 14). ${ }^{4}$ With active contraction, sarcomere length is linearly related to changes in circumference of the fixed LV (Fig 14). ${ }^{5,47}$ These data imply that $13 \%$ midwall sarcomere shortening is all that is needed to power the normal canine LV through ejection fractions greater than 50\% and systolic increases in wall thickness of $30 \%$ to $49 \%$ (Figs 4 and 19). Preload is currently believed to influence force generation in cardiac muscle through effects on calcium transport, as well as through effects on actin-myosin overlap in the sarcomere. ${ }^{51}$ The gradient of sarcomere lengths and strains across the LV wall during changes in volume has been contested on the basis of contradictory data from numerous sources ${ }^{50}$ and should be regarded as incompletely defined.

In passively fixed hearts, shortened sarcomeres are difficult to demonstrate (Figs 12 and 13). During systole, the endocardial layers buckle inward (Fig 2). Negative pressure is required to completely empty the
$\mathrm{LV}$, and the volume of the arrested $\mathrm{LV}$ open to the atmosphere is greater than zero, averaging $12 \mathrm{~mL}$ in the dog. ${ }^{4}$ Internal stresses in the LV wall appear to keep sarcomeres extended in the absence of electrical activation. The source of these internal stresses resides in part in the complex fiber weave of the ventricular wall, which will now be described.

Fiber angles. Quantitative myocardial histology requires accurate relation of the three-dimensional, orthogonal reference system used to position tissue blocks for sectioning to the polar reference system of the intact ventricle (Fig 7). Ideally, the ventricle is fixed with chamber pressure and volume controlled to reflect the physiologic conditions observed in vivo. Next, the ventricle is mounted in an apparatus facilitating cuts parallel to the circumferential plane. Two such cuts produce a ring of tissue. Two vertical cuts in such a ring produce a roughly rectangular block whose surfaces consist of epicardium, endocardium, two circumferential cuts, and two meridional cuts.

This general method has been used to study the orientation of the LV myocardial fibers. The results can be described in reference to the circumferential plane, which has a fiber angle of zero. ${ }^{2}$ Predominant orientation of myocardial fibers varies with wall thickness, 

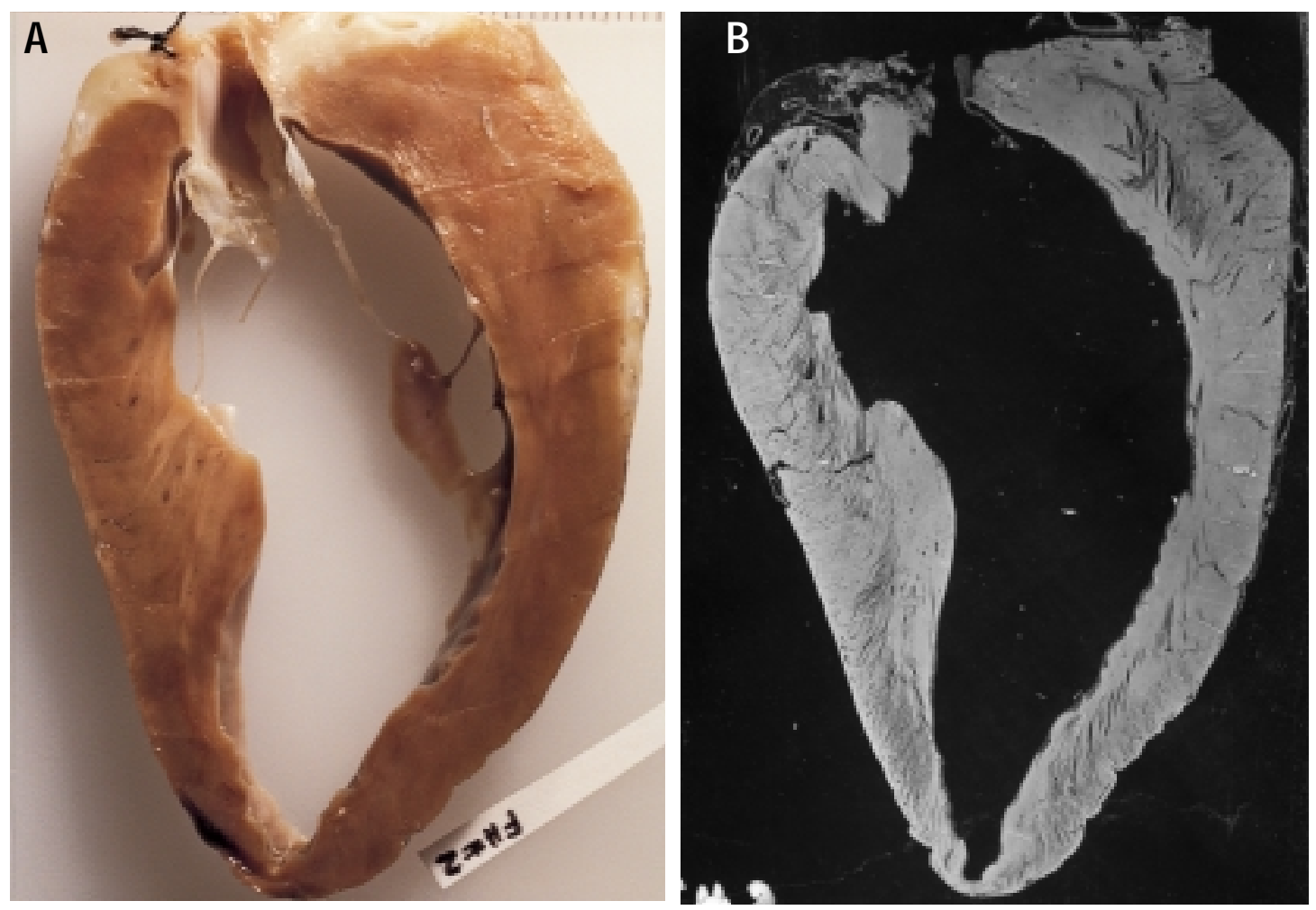

Fig 8. Longitudinal section of cut surface of immature, unfixed LV on the left (A) and corresponding frozen section on the right (B). Variation in wall thickness and radius of curvature is apparent. Smallest radius and thinnest wall are at the apex. A papillary muscle bulge is apparent at midwall on the left. Cleavage planes appear in the frozen section and contribute a characteristic pattern. These cleavage planes are not seen in the fresh ventricle, suggesting that they are created along intercellular boundaries by processing. (Spotnitz WD, Spotnitz HM, unpublished data.)

and the pattern is reminiscent of multiple concentric layers of hoops (Figs 4 and 15-17). At midwall, halfway between the epicardium and endocardium, the fibers lie in the circumferential plane, aligned with short-axis sections perpendicular to the long axis. In the $10 \%$ of wall thickness closest to the endocardial surface, fibers course upward to the right, averaging $+60^{\circ}$ oblique to the circumferential plane (Figs 1517). In the $10 \%$ of wall thickness closest to the epicardial surface, the fiber angle is downward to the right, averaging $-60^{\circ}$ oblique to the circumferential plane and overlapping the endocardial fibers at a $120^{\circ}$ angle. At the endocardial and epicardial surfaces, fibers are vertical in some areas, parallel to the long axis. All intervening fiber angles are represented, and fiber orientation varies gradually with depth within the wall between the limits described. ${ }^{2}$ An observer facing an upright LV with its apex pointed toward the floor and its base toward the ceiling would observe fibers on the epicardial surface coursing obliquely downward and to the right.
Fiber angle in systolic contraction. Systole has little effect on the array of fiber angles across the wall, but all angles are decreased by an increment of $10^{\circ}$ to $15^{\circ}$ that suggests torsion of the entire wall relative to the long axis (Fig 17). ${ }^{2}$ The array of force vectors suggests that systolic activation constricts the LV more powerfully circumferentially than in the (meridional) direction of the long axis. Although contraction of fibers oriented $60^{\circ}$ toward the apex tends to shorten the $\mathrm{LV}$ in the apex-base direction, some force is also exerted in the circumferential direction. ${ }^{2,54}$ When all the fiber directions and force vectors in the LV wall are summed, circumferential shortening is favored. Experimentally, systolic contraction narrows the circumference of the LV more than its length. ${ }^{6,7,14-16,54,55} \mathrm{In}$ the normal LV the long axis/short axis ratio is less than 2:1 at end-diastole and more than 2:1 at end-systole. ${ }^{6,7,16}$ In the dog heart, nearly $90 \%$ of stroke volume is due to minor axis (circumferential) shortening, and variation of LV shape during the cardiac cycle is a function of end-diastolic volume. ${ }^{14,15}$ 


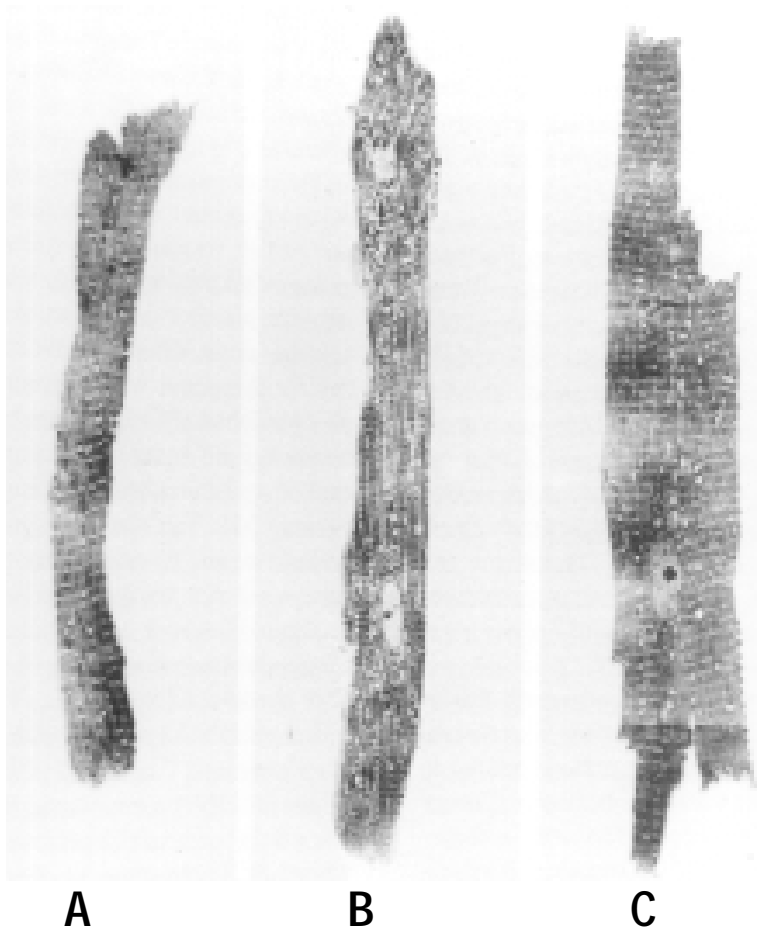

Fig 9. Photomontages assembled from electron micrographs of dog LV. Cells are from control (A), congestive heart failure due to mitral regurgitation $(\mathbf{B})$, and recovery state after successful mitral valve surgery (C). Recovery from failure is associated with recovery of normal sarcomere architecture, but cells remain enlarged and thickened compared with the control state (From Spinale FG, Ishihra K, Zile M, DeFryte G, Crawford FA, Carabello BA. Structural basis for changes in left ventricular function and geometry because of chronic mitral regurgitation and after correction of volume overload. J Thorac Cardiovasc Surg 1993;106:1147-57. Reprinted with permission of Mosby, Inc.)

Fiber angle and physiologic studies. Physiologically, the directions of greatest interest in the LV wall are (1) coincident with principal local fiber direction and (2) perpendicular to it, the "cross-fiber direction." 3,56 Myocardial cells are optimized to shorten along their long axis; this drives systolic contraction. Dimension changes or "strains" coincident with fiber orientation can be understood in terms of sarcomere length, which is physiologic preload. ${ }^{4,50}$ Fiber direction must be known to orient sections properly for measurement of sarcomere length.

Fiber shortening and extension parallel to fiber orientation is intuitive and easy to understand. Conversely, shortening in the cross-fiber direction is counterintuitive, difficult to understand, and physiologically very important. The analysis of cross-fiber movement and the anatomic structures that facilitate such movement

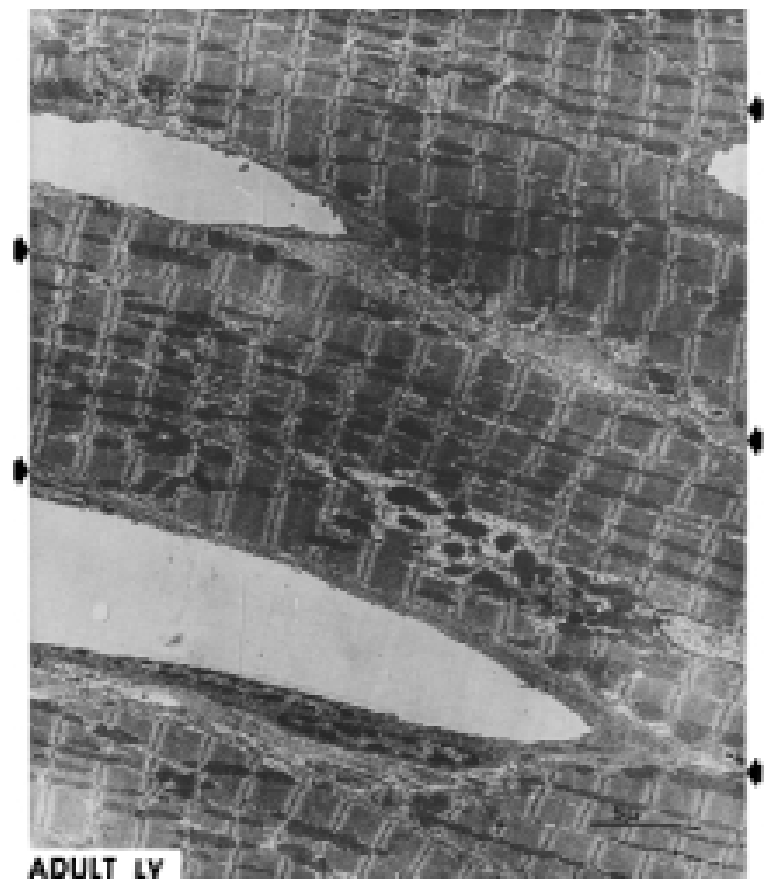

Fig 10. Electron micrograph of adult LV canine myocardium. ${ }^{4,45}$ Long axes of several cells cross the figure from left to right. Arrows mark the location of boundaries between adjacent cells. Large open spaces are capillaries perfused with fixative. Alternating band patterns from left to right are sarcomeres, consisting of a wide, dark central A band and a light I band on each end. Each I band is divided into two halves by a central, dark Z-line that defines the end of the sarcomere. Two light lines in the center of each A band are part of the ML complex. Rounded and/or elongated structures between rows of sarcomeres are mitochondria, sites of oxidative phosphorylation. (From Spotnitz WD, Spotnitz HM, Truccone NJ, Cottrell TS, Gersony W, Malm JR, et al. Relation of ultrastructure to function: sarcomere dimensions, pressure volume curves, and geometry of the intact left ventricle of the immature canine heart. Circ Res 1979;44:679-91. Reprinted with permission of Lippincott Williams \& Wilkins.)

requires meticulous attention to the proper sectioning planes, and many planes are required. NMR tagging is particularly versatile in tracking strains over a large number of vectors in three-dimensional space. ${ }^{10,11}$ However, as will be discussed, myocardial strains are average deformations, so that components both larger and smaller than the mean may be present and go undetected.

Cross-fiber shortening. During systole, LV ejection fraction $(50 \%-70 \%)$ and increases in wall thickness $(30 \%-50 \%)$ vastly exceed circumferential strains and sarcomere shortening (10\%-20\%) (Figs 4, 18, and 19). This dimensional divergence reflects an ingenious nat- 


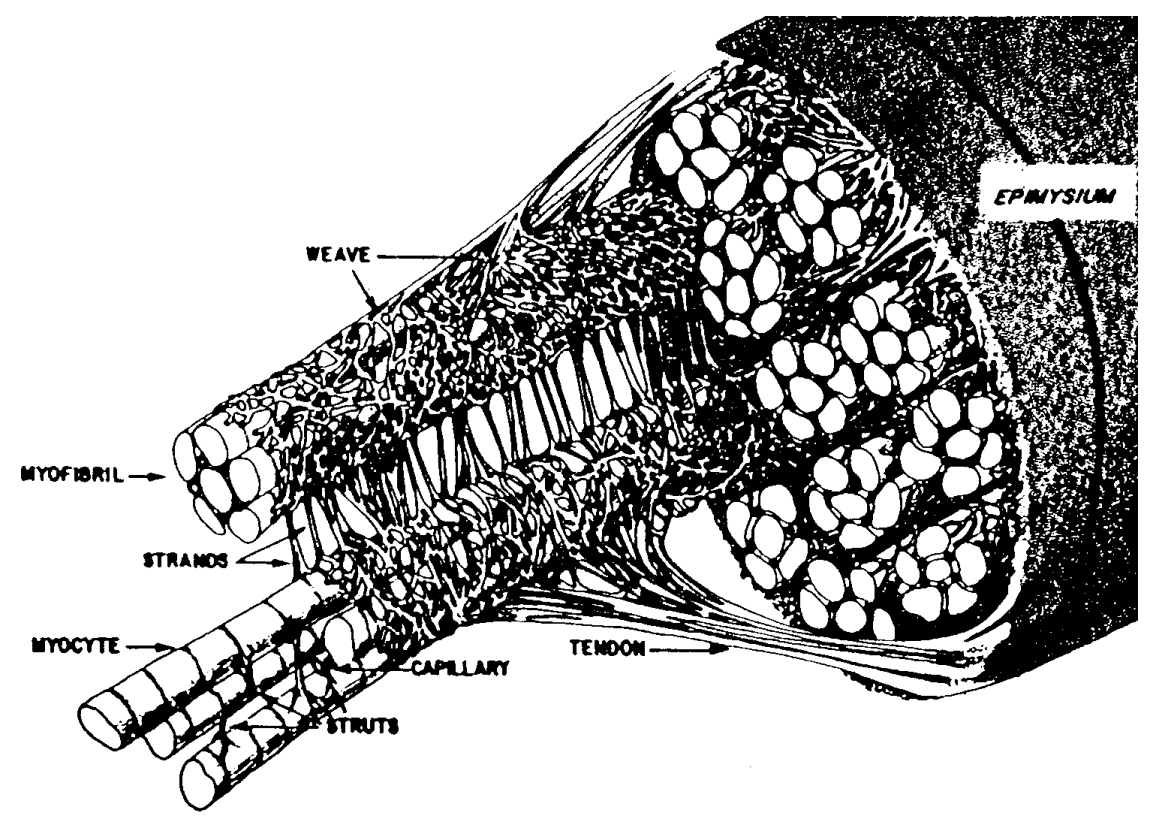

Fig 11. Schematic illustration of substructure of the connective tissue matrix of the myocardium (From Weber K. Cardiac interstitium in health and disease: the fibrillar collagen network. Reprinted with permission from the American College of Cardiology J Am Coll Cardiol 1989;7:1637-52.)

ural implementation of basic solid geometry. ${ }^{3}$ Simple models illustrate what aspects of this are straightforward and where obfuscation and uncertainty remain.

\section{Modeling techniques}

The simplest geometric model is two concentric spheres, one for the endocardial shell and one for the epicardial shell. ${ }^{3}$ Dimension changes during the cardiac cycle are symmetrical around the center of mass and can be calculated with a spreadsheet. An alternate model, an ellipsoid of revolution with a 2:1 long axis/short axis relation, is closer to reality. ${ }^{34} \mathrm{Cal}-$ culations are relatively simple for an ellipsoid, if it is assumed that wall thickness is uniform and that dimension changes are symmetrical along the long axis and the two principal short-axis diameters. Tapering wall thickness and asymmetric contraction add more complexity than can be handled by simple calculations. The true physiologic situation, in which radius of curvature, sarcomere length, fiber orientation, wall thickness, and electrical activation vary widely with location within the ventricular wall ${ }^{36}$ and from moment to moment, require advanced techniques like finite element analysis $^{57}$ and powerful supercomputers. Even so, the problem becomes overwhelming if detail is extensive. Geometric, finite element, and multiple compartment elastance models ${ }^{57}$ have been defined to analyze the effect on global LV function of addition or resection of normally functioning or akinetic wall segments (Figs 20 and 21).

\section{Compressibility of the $\mathrm{LV}$ wall}

Most LV models postulate that the LV wall is incompressible, so that LV mass and wall volume remain constant during the cardiac cycle. Components of the LV wall that may be compressible under physiologic conditions are primarily the vasculature and lymphatics, which compose less than $10 \%$ of LV mass. ${ }^{39}$ Experimental data based on large numbers of dynamic sections support the view that LV mass remains constant during the cardiac cycle. ${ }^{9,14}$ Reactive hyperemia and myocardial edema can occur suddenly and may produce measurable changes in LV mass over a few minutes. ${ }^{37,58}$ These phenomena are not believed to render LV mass susceptible to variation during the cardiac cycle. The discussion that follows assumes that $\mathrm{LV}$ wall volume is constant.

\section{Thick-wall geometry}

In a soap bubble, a $50 \%$ decrease in volume requires a $21 \%$ decrease in radius and circumference. Because wall thickness is trivial to begin with, changes in thickness are not important. A thick-walled sphere differs qualitatively, because when wall volume is a significant fraction of total volume (wall plus chamber), the mass of the wall becomes an increasing fraction of the whole as chamber volume decreases. Stated another way, as 


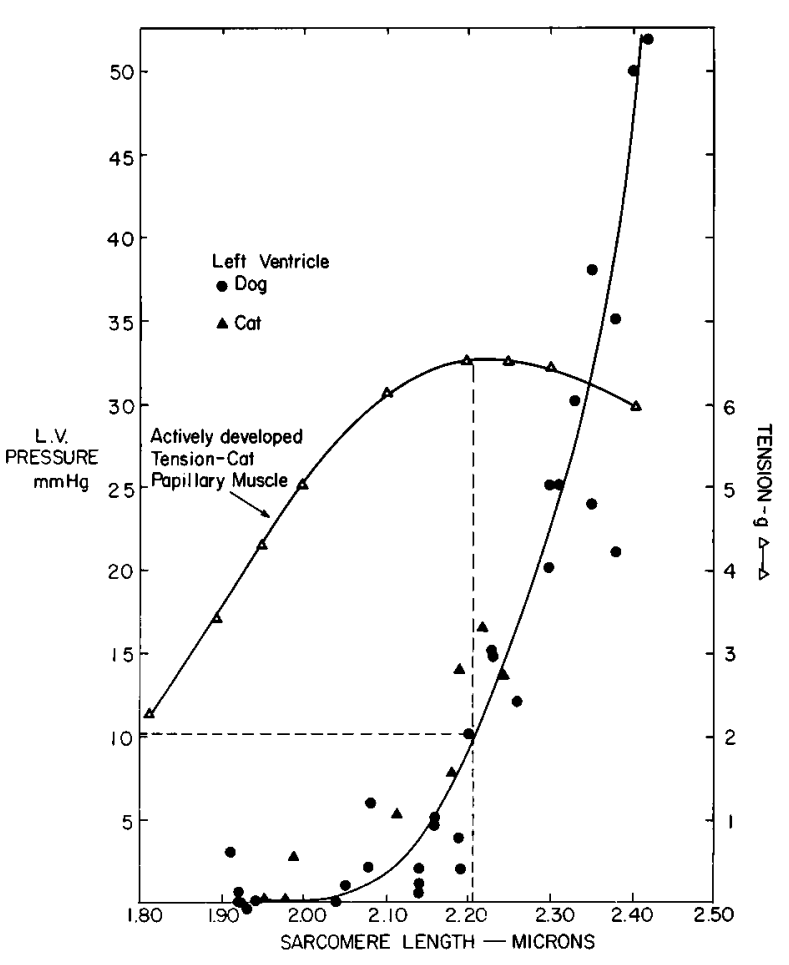

Fig 12. Sarcomere length-fixation pressure relation for the midwall myocardial layer of dog and cat is compared with the sarcomere length-active tension relation for cat papillary muscle. The papillary muscle data ${ }^{79}$ are consistent with the sliding filament hypothesis and indicate that a sarcomere length of $2.2 \mu \mathrm{m}$ is optimal for force generation. The intact LV data ${ }^{4}$ indicate that the optimum sarcomere length of 2.2 $\mu \mathrm{m}$ is achieved at midwall with a filling pressure of 10 to 12 $\mathrm{mm} \mathrm{Hg}$. Sarcomere lengths shorter than $1.9 \mu \mathrm{m}$ are not observed with diastolic potassium arrest. (From Spotnitz HM, Sonnenblick EH, Spiro D. Relation of ultrastructure to function in the intact heart: sarcomere structure relative to pressure volume curves of intact left ventricles of the dog and cat. Circ Res 1966;18:49-66. Reprinted with permission of Lippincott Williams \& Wilkins.)

chamber volume decreases, the surface area over which wall volume is distributed diminishes and wall volume must be distributed over a shrinking surface. This requires large increases in wall thickness. ${ }^{7,14-16,29,37}$

\section{Assumptions}

Modeling this behavior incorporates the following characteristics, definitions, and assumptions: The LV wall volume is constant and is numerically similar to chamber volume. LV wall thickness is similar to chamber radius. The volume of the myocardium is roughly equal to its mass (the specific gravity of myocardium is 1.055). Calculations are based on the normal dog LV

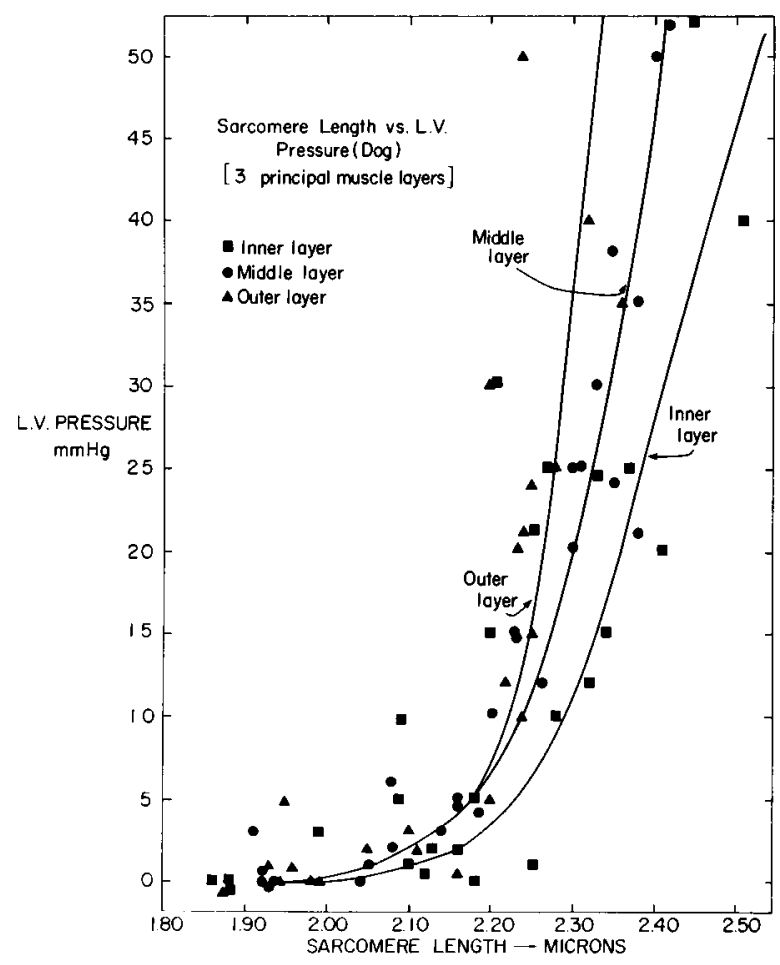

Fig 13. Relation of sarcomere length to fixation pressure for three myocardial layers in LV of the dog. The data suggest that a wider range of sarcomere lengths occurs at the inner third than is observed in the outer third, consistent with geometric models of the LV. (From Spotnitz HM, Sonnenblick $\mathrm{EH}$, Spiro D. Relation of ultrastructure to function in the intact heart: sarcomere structure relative to pressure volume curves of intact left ventricles of the dog and cat. Circ Res 1966;18:49-66. Reprinted with permission of Lippincott Williams \& Wilkins.)

with a mass of $100 \mathrm{~g}$ and $\mathrm{LV}$ end-diastolic volume of 50 $\mathrm{mL}$, for comparison with relevant experimental data. In normal human beings, LV end-diastolic volume averages 100 to $125 \mathrm{~mL}$ and $\mathrm{LV}$ mass averages $150 \mathrm{~g}$. 7,59

\section{Calculations}

The endocardial radius (Ri) can be calculated simplistically from a $100-\mathrm{mL}$ sphere as $50=(4 / 3)\left(\pi \mathrm{Ri}^{3}\right)$. The epicardial radius (Ro) can similarly be calculated from the geometry of a 50 (end-diastolic volume) $+100(\mathrm{LV}$ wall $)=150-\mathrm{mL}$ sphere. If the ejection fraction is $60 \%$, end-systolic endocardial radius (Ri) will be given by a 20-mL sphere and end-systolic epicardial radius (Ro) by a $20+100=120-\mathrm{mL}$ sphere. During systole, the epicardial volume will decrease by $60 / 100=60 \%$, while the chamber volume determining the endocardial radius will decrease by $60 / 150=40 \%$. Corresponding changes in radius and circumference are as follows: epicardial $7 \%$, 


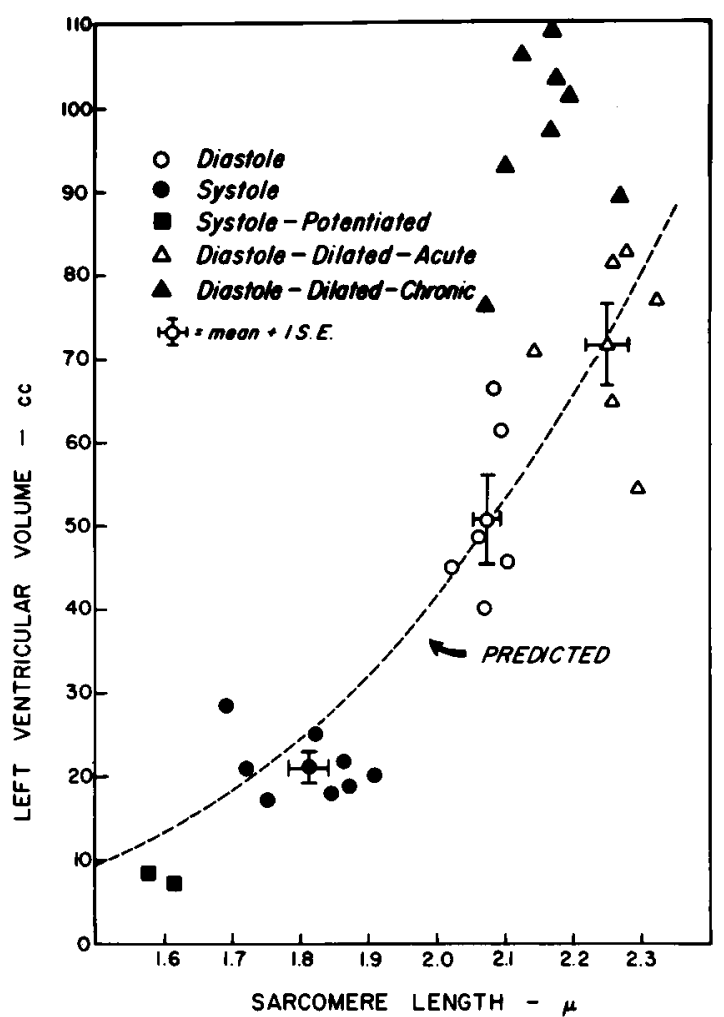

Fig 14. Relation between sarcomere length and fixation volume in midwall myocardial layer of dog in control and pathologic states. Diastolic fixation conditions are similar to Figs 12 and 13. Acute dilation was produced by raising fixation pressure to levels observed in dogs with an acute aortocaval fistula. Chronic dilation was observed after 6 weeks of aortocaval fistula. Systolic LVs were obtained by timed coronary injection of fixative. In contrast to sarcomere lengths in passively fixed hearts, sarcomere lengths less than $1.9 \mu \mathrm{m}$ are observed. Sarcomere length in the chronically dilated heart is shorter than expected for the volumes measured, based on a spherical model. This suggests internal rearrangement of the relation between sarcomere length and volume. $S E$, Standard error. (Data from reference 47.)

midwall $15 \%$, and endocardial $26 \% .^{4,8}$ Calculated wall thickness increases $36 \%$. Any given change in chamber volume will produce a much larger change in radius and circumference at the endocardium than at the midwall and epicardium 4 (Fig 22).

Thus amplification of $15 \%$ fiber shortening to an ejection fraction of $60 \%$ and an increase in wall thickness of $36 \%$ (Fig 19) results directly from the laws of solid geometry and conservation of mass. These results are essentially unchanged when calculations are based on an ellipsoid of revolution. ${ }^{34}$

Solid geometry readily explains how $15 \%$ circumferential sarcomere shortening can produce large changes

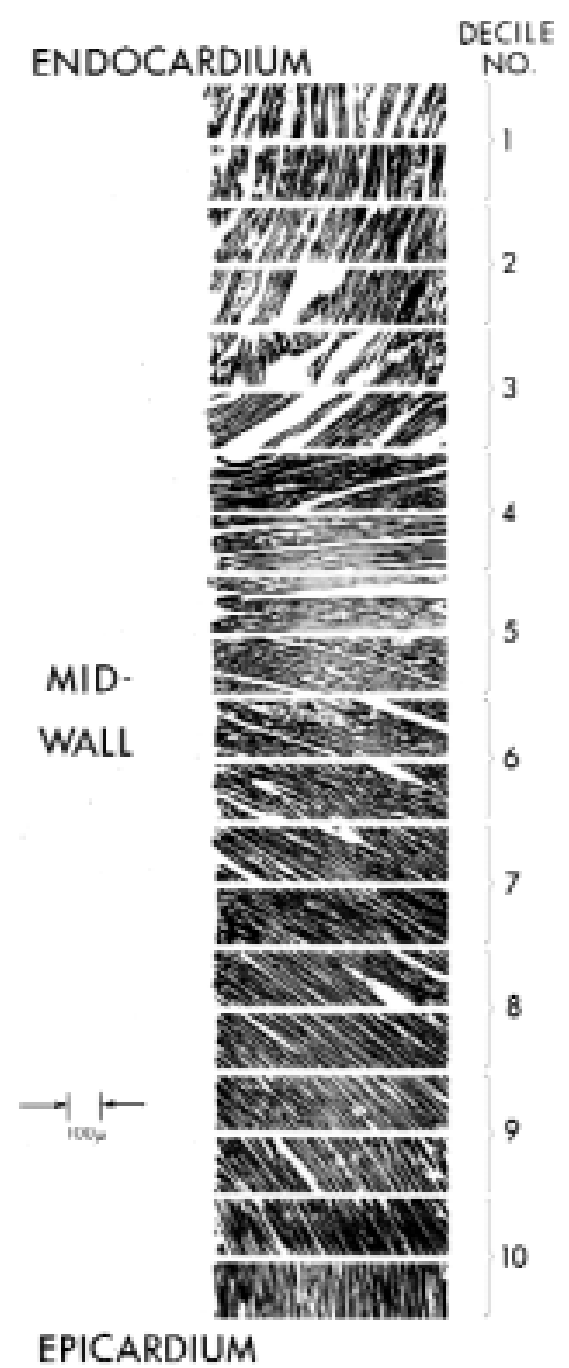

Fig 15. Serial sections across the LV wall illustrate fiber orientation. The long edge of each section was cut parallel to the circumferential plane as indicated in Fig 7. Sections in the region between deciles 4 and 5 reveal circumferential fiber orientation at an angle of $0^{\circ}$ relative to the reference plane. Fiber angle increases gradually in opposite directions in sections approaching the epicardial and endocardial surfaces. Sections close to the surface in this example reveal fiber angles of $90^{\circ}$. (From Streeter DD Jr, Spotnitz HM, Patel DP, Ross J Jr, Sonnenblick EH. Fiber orientation in the canine left ventricle during systole and diastole. Circ Res 1969;24:339-47. Reprinted with permission of Lippincott Williams \& Wilkins.)

in wall thickness and chamber volume. ${ }^{3,34}$ However, other issues are not resolved by modeling or experimental data. In particular, how exactly do dimensional changes in the cross-fiber direction occur? This is discussed further in the next section. 
THE MYOCARDIAL CONTINOUM

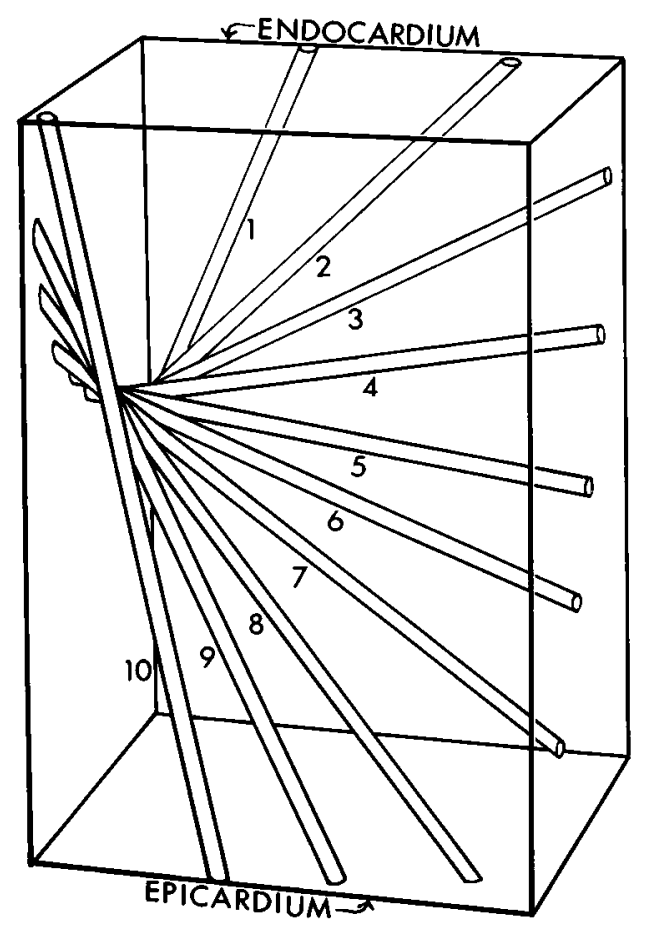

Fig 16. Idealized, three-dimensional segment of the LV wall illustrates mean fiber orientation. The apex-base direction is vertical in this figure, and the horizontal edges of the block are parallel to the circumferential plane. (Data from reference 2.)

\section{Mechanisms of wall thickening/cross-fiber thickening}

If fibers behave like cylinders of constant volume, $13 \%$ fiber shortening will increase cross-sectional area 13\% and increase fiber thickness $6 \%$ (Fig 4). ${ }^{3,54}$ How can wall thickness increase $36 \%$ when fiber thickness increases $6 \%$ ? This requires displacement of myocardium, increasing the number of fibers aligned radially across the wall as wall thickness increases. In rat hearts, phasecontrast microscopy of the full thickness of the LV wall demonstrates that the rate of change of wall thickness, which matches predictions based on LV volume, is too great to be explained by changes in fiber thickness. Although small changes in fiber thickness and packing do occur, changes in wall thickness are more closely related to the number of fibers aligned across the wall than to fiber dimensions (Fig 23). ${ }^{3}$ A relation between wall thickness and the number of fibers aligned across the wall has also been demonstrated in wall thinning after myocardial infarction (Fig 24) ${ }^{60}$

As discussed above, the laws of solid geometry for a sphere require that as ventricular volume decreases merid-

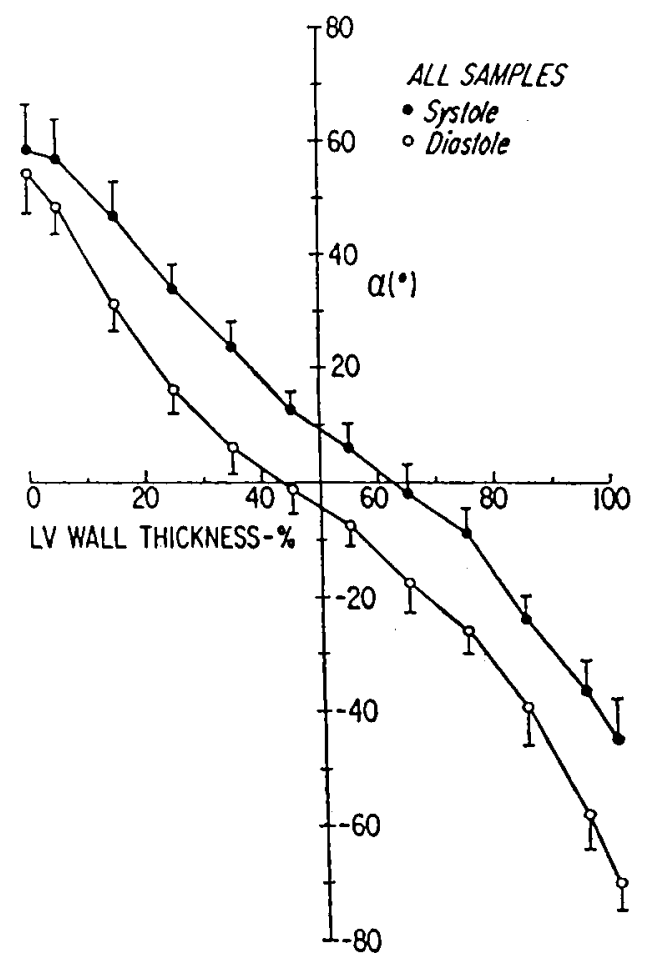

Fig 17. LV myocardial fiber angles, averaged for $10 \%$ increments (deciles) across the wall. Fibers halfway between the endocardium and epicardium are circumferential, at a fiber angle of $0^{\circ}$. Fibers at the endocardial and epicardial surface overlap at a $120^{\circ}$ angle and form opposite $60^{\circ}$ angles with circumferential midwall fibers. Fiber angles vary gradually between these extremes. More than $60 \%$ of fibers lie within $\pm 22^{\circ}$ of circumferential orientation. ${ }^{5}$ A minimal effect of systolic contraction on the distribution of fiber angles is illustrated and is consistent with a twisting motion of the anterior wall in systole. These hearts were arrested during systole by coronary injection. (From Streeter DD Jr, Spotnitz HM, Patel DP, Ross J Jr, Sonnenblick EH. Fiber orientation in the canine left ventricle during systole and diastole. Circ Res 1969;24:339-47. Reprinted with permission of Lippincott Williams \& Wilkins.)

ional circumference also decreases, while wall thickness increases. Fig 18 demonstrates that for the number of transected fibers presenting at the cut surface of such a ventricle to remain constant, fibers must move from a side-toside alignment in the meridional direction in favor of the radial direction. Conversely, fibers must realign themselves from the radial configuration to the meridional as volume and circumference increase and wall thickness attenuates. ${ }^{3,61-63}$ One possible mechanism for this, based on movement of shingle-like groups of fibers separated by sliding planes, is illustrated in Fig 25. Other postulated mechanisms have included two adjacent rows of fibers becoming one by alternate interleaving of fibers. ${ }^{63}$ 


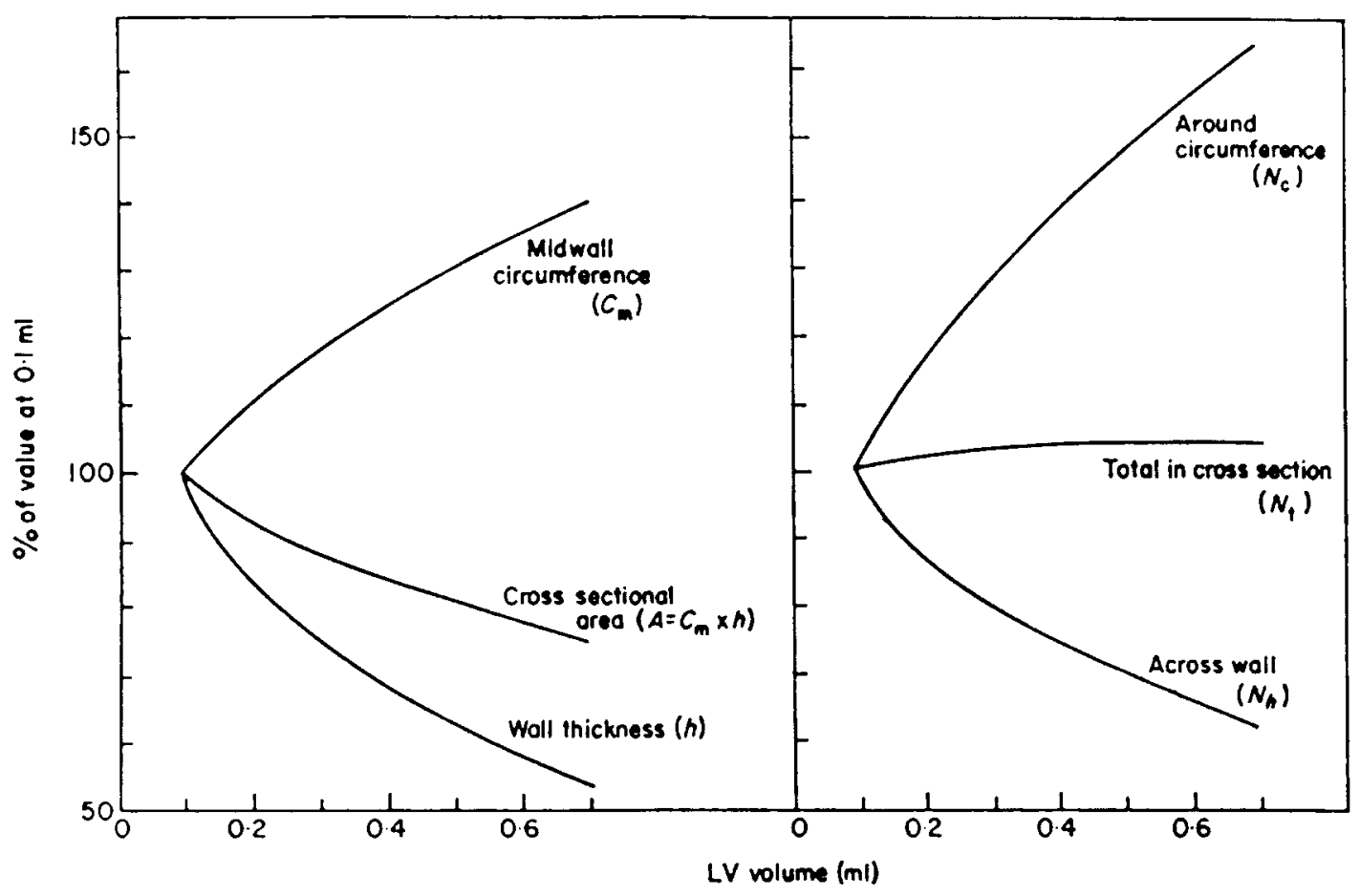

Fig 18. Calculations based on a spherical model for effect of changing volume on LV dimensions. The left panel demonstrates increasing midwall circumference $(\mathrm{Cm})$, decreasing wall thickness $(\mathrm{h})$, and decreasing area of equatorial myocardial ring $(A)$ as LV volume increases. The right panel indicates calculated changes in fiber distribution. All fibers are assumed perpendicular to the cut surface, presenting as transected cylinders. Diameter and crosssectional area of the fibers change in accordance with the mean change in cell length (circumference of ventricle). As volume increases and the wall thins, the number of fibers perpendicular to the circumference $(N c)$ increases and the number aligned across the wall $(\mathrm{Nh})$ decreases, whereas the total number of fibers $(\mathrm{Nt})$ does not change. (From Spotnitz HM, Spotnitz WD, Cottrell TS, Spiro D, Sonnenblick EH. Cellular basis for volume related wall thickness changes in the rat left ventricle. J Mol Cell Cardiol 1974;6:317-31. Reprinted with permission of Academic Press, Ltd.)

Histologic support for the concept of movement of subgroups of fibers is provided by cleavage planes. ${ }^{3,62,63}$ These planes appear to be fixation artifacts that result from tissues separating along cell boundaries during dehydration (Figs 8 and 26-28). The orientation of these planes in fixed hearts changes in a way that would facilitate changes in wall thickness (Figs 28-31).,62,63 NMR tagging studies confirm cross-fiber movement during changes in wall thickness ${ }^{56}$ but do not provide sufficient resolution, as yet, to define what path the fibers actually follow. Fiber movement out of the NMR sectioning plane is also a problem. ${ }^{10,11}$ The pattern of cleavage planes in histologic sections is highly dependent on the sectioning plane, ${ }^{61,62}$ and it is not likely that the full pattern of fiber movement will be defined for some time. Tethering effects of myocardial scarring or edema would be expected to impede the efficiency of systolic fiber rearrangements and impair the efficiency of systolic contraction.

\section{Systolic torsion of the $\mathbf{L V}$}

The symmetry of the LV fiber matrix could result in neutralization of opposed twisting forces at the epicardial and endocardial surfaces (Fig 32). This would result in no torsion of the LV, whereas torsion is easily demonstrated. It has been proposed ${ }^{13}$ that asymmetry of fiber radii, sarcomere length, and electrical activation allows torsion of the apex relative to the base (Fig 5). In fact, systolic torsion of the LV is widely recognized and has been extensively characterized with studies in which implanted markers (Fig 33) ${ }^{12,13,64}$ and NMR tagging are used (Fig 34). ${ }^{10,11}$ During systole, the apex ("counterclockwise") and base ("clockwise") rotate in opposite directions. ${ }^{10}$ These movements are exaggerated and slowed by aortic stenosis. ${ }^{10}$ Clinical data in Figs 33 and 34 demonstrate that the LV twist accumulated during systole reverses rapidly in early diastole. This common finding suggests elastic recoil and is useful for study of diastolic filling. ${ }^{11}$ Studies of the patterns of torque in various forms of 


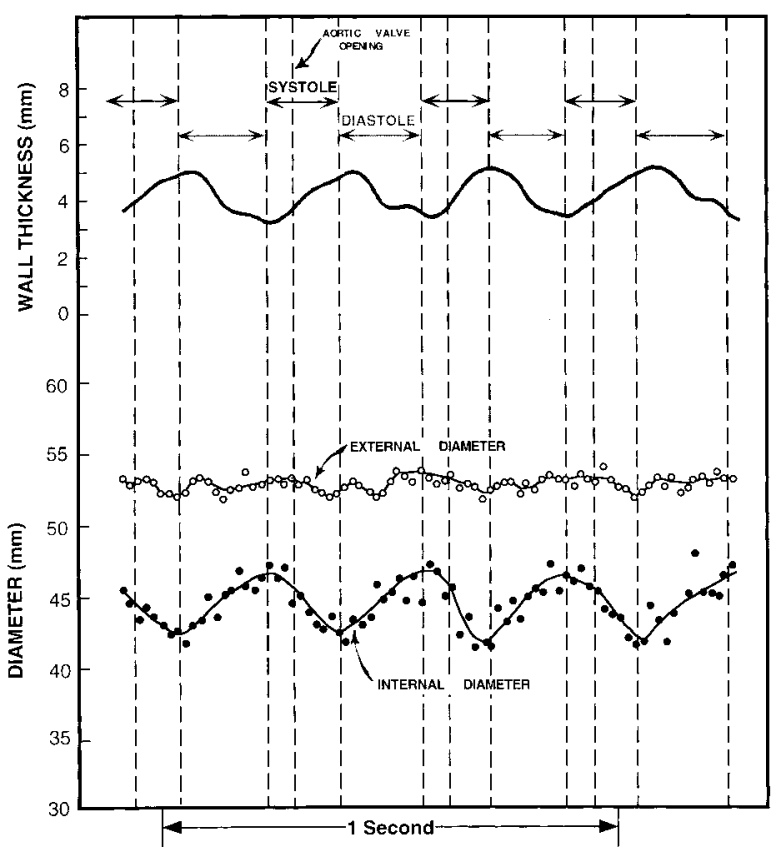

Fig 19. Data from $x$-ray contrast angiograms for diameter and wall thickness in the LV of the normal dog during the cardiac cycle. Wall thickness increases more than $40 \%$ during systole, whereas epicardial diameter increases less than $10 \%$. (Modified from Mitchell JH, Wildenthal K, Mullins CB. Geometric studies of the left ventricle utilizing biplane cinefluorography. Fed Proc 1969;28:1334-43. Reprinted with permission of the Federation of the American Society for Experimental Biology.)

hypertrophy and dysfunction have revealed characteristic patterns. ${ }^{10,64} \mathrm{NMR}$ tagging is a powerful tool that should evolve to forms valuable for both basic science and clinical management.

\section{The mitral valve and papillary muscles}

In normal human beings the mitral valve anulus is rounder in diastole and more ellipsoidal in systole. ${ }^{65} \mathrm{An}$ ellipsoidal LV cross section has also been described in transplant rejection. ${ }^{66}$ A $26 \%$ decrease in mitral orifice area and a $13 \%$ decrease in mitral circumference have been reported during normal systolic contraction. ${ }^{65}$

Knowledge of papillary muscle function in experimental animals has been summarized. ${ }^{26}$ Experimental evidence indicates that the papillary muscles and chordae tendineae contribute to changes in ventricular shape during isovolumetric systole and to force generation in systole.

The concept that chordal preservation is important to LV function after mitral valve surgery is increasingly accepted. Potentially adverse effects of disruption of

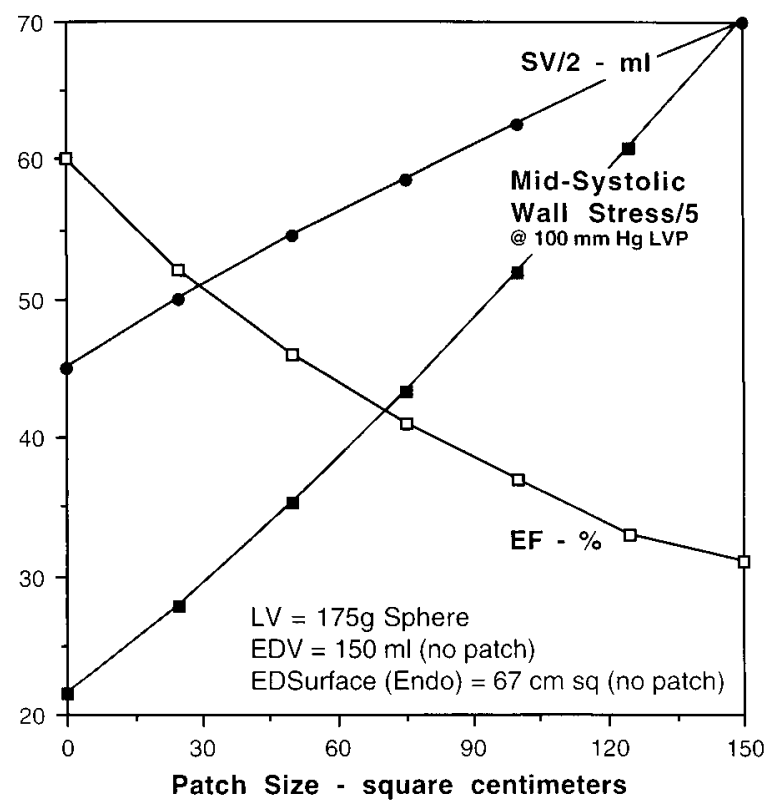

Fig 20. Calculated effects of changing patch size on function, derived from a spherical LV model. The model is assumed to remain spherical regardless of patch size, and the area change of the normal surface is assumed to remain constant, although these idealized conditions cannot be achieved in reality. The calculations indicate that both stroke volume and wall stress increase, while ejection fraction decreases, with increasing patch size. Theoretically, any desired level of stroke volume could be achieved by adding a patch of sufficient size. The limitation, however, is that when wall stress become high enough, afterload mismatch will result and the ventricle will fail. Patch repair LV aneurysmectomy and LV reduction surgery seek to move the LV from right to left in this diagram, reducing wall stress without making stroke volume too small. $S V$, Stroke volume; $L V P$, left ventricular pressure; $E D V$, enddiastolic volume. (From Nicolosi AC, Weng Z-C, Detwiler PW, Spotnitz HM. Simulated left ventricular aneurysm and aneurysm repair in swine. J Thorac Cardiovasc Surg 1990;100:745-55. Reprinted with permission of Mosby, Inc.)

the papillary muscle apparatus and of a rigid ring in the mitral anulus have been incorporated into mitral valve repair surgery. ${ }^{21-26}$

\section{Wall forces: Effects of altered geometry and loading}

As noted above, LV wall thickness and radius relate chamber pressure to myocardial wall stress. This is expressed most simply by a modified Laplace relation, $S=P \times(r / 2 h)$, where $S$ is cross-sectional force per unit 

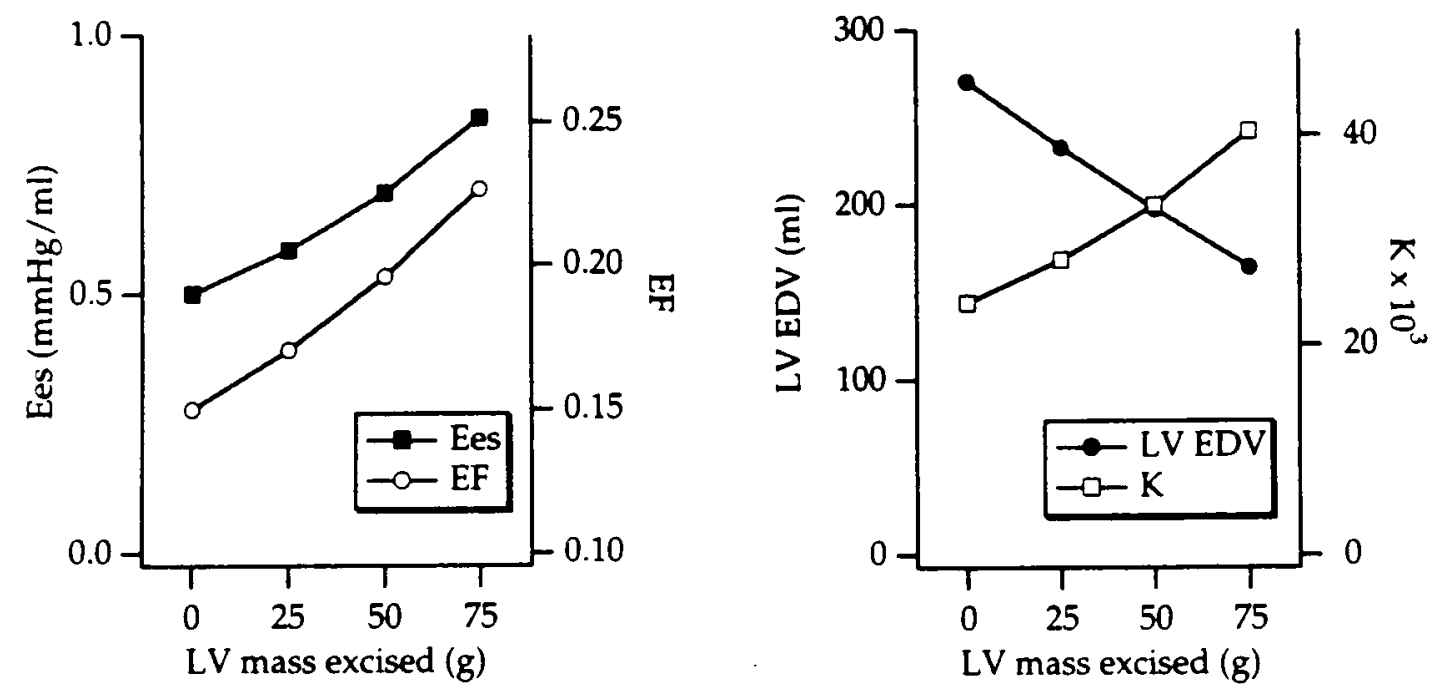

Fig 21. Calculated effects of volume reduction on LV function. Resection of normal myocardium increases elastance (Ees), ejection fraction $(E F)$, and diastolic stiffness $(K)$ while LV end-diastolic volume $(L V E D V)$ decreases. Data are based on finite element analysis. (From Dickstein ML, Spotnitz HM, Rose EA, Burkhoff D. Heart reduction surgery: an analysis of the impact on cardiac function. J Thorac Cardiovasc Surg 1997;113:1032-40. Reprinted with permission of Mosby, Inc.)

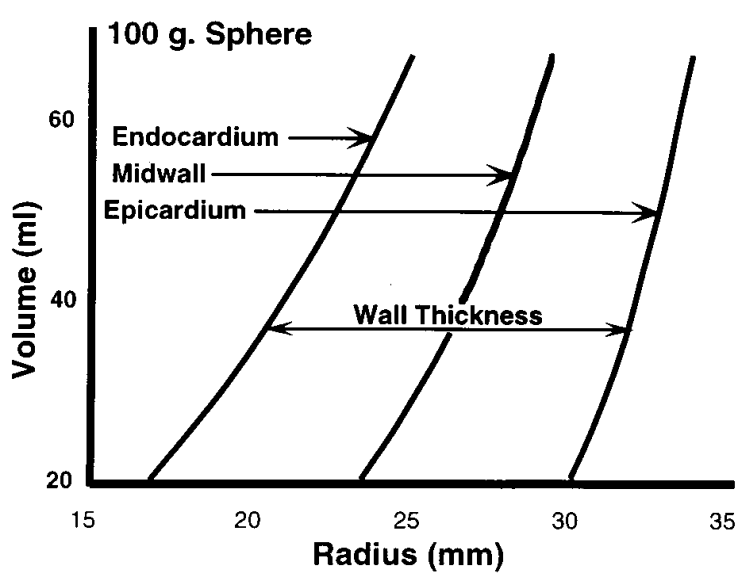

Fig 22. Relation between radii and chamber volume calculated for a 100-g spherical model of the LV. Curves are drawn for the endocardial surface, epicardial surface, and midwall. The distance between the epicardial and endocardial curves at any given volume represents wall thickness. Percentage changes in wall thickness are larger than percentage changes in radius for any given increment of volume. Thick-wall geometry requires largest changes in radius at the endocardial surface. Conversely, small dimension changes at the epicardial surface can produce large changes in wall thickness and chamber volume. (From Spotnitz HM, Antunes ML. Effect of aortic and mitral regurgitation on left ventricular structure and function. Adv Card Surg 1991;2:85-116. Reprinted with permission of Mosby, Inc.)

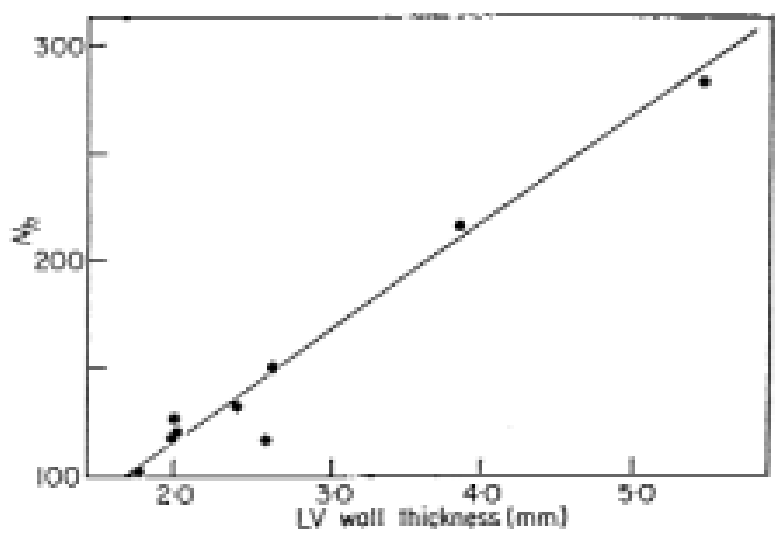

Fig 23. Relation between wall thickness and fiber counts (Nh) across the ventricular wall in the rat LV. Changes in wall thickness relate more closely to changes in Nh than any other histologic parameter studied. (From Spotnitz HM, Spotnitz WD, Cottrell TS, Spiro D, Sonnenblick EH. Cellular basis for volume related wall thickness changes in the rat left ventricle. J Mol Cell Cardiol 1974;6:317-31. Reprinted with permission of Academic Press, Ltd.)

area in the wall, $P$ is pressure in the ventricle, $r$ is endocardial radius, and $h$ is wall thickness. ${ }^{35}$ This equation, as well as more complex approaches, ${ }^{4,7,36,67-71}$ allow effects of both acute and chronic geometric changes on fiber loading to be estimated. 


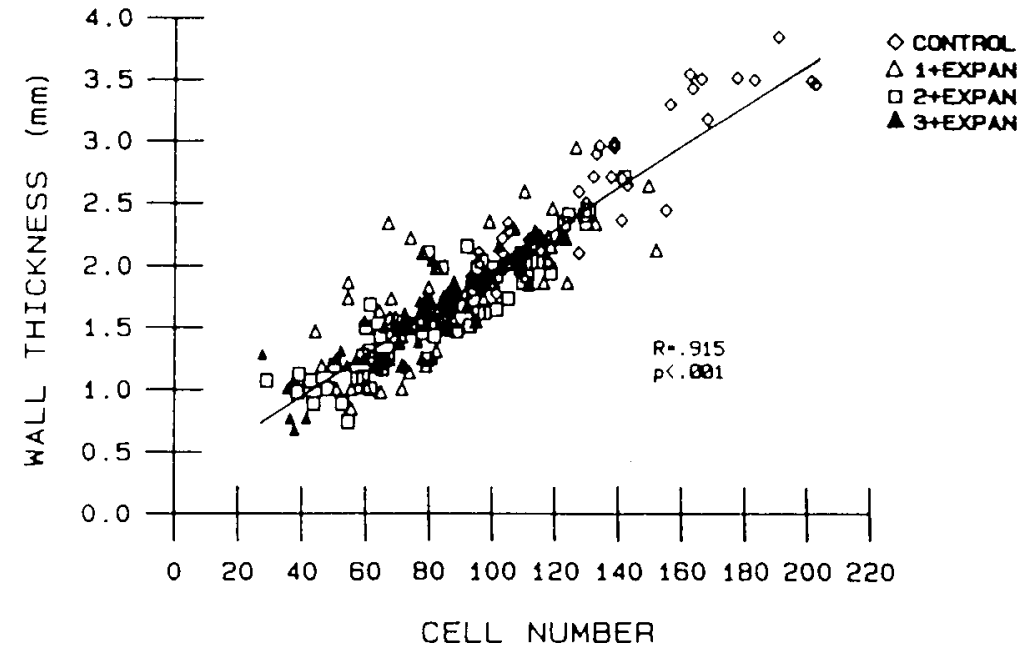

Fig 24. As in Fig 23, these data indicate that changes in wall thickness during infarct expansion are primarily related to a decrease in the number of fibers aligned across the wall. (From Weisman HF, Bush DE, Mannisi JA, Weisfeldt ML, Healy B. Cellular mechanisms of myocardial infarct expansion. Circulation 1988;78:186-201. Reprinted with permission of Lippincott Williams \& Wilkins.)
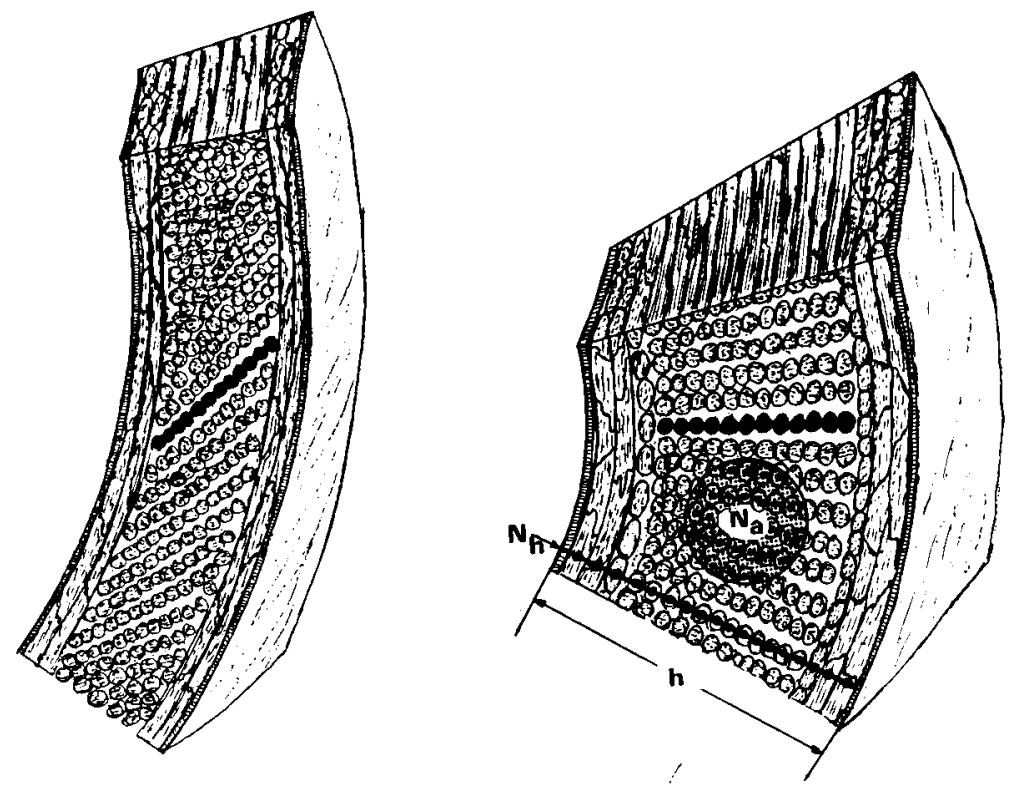

Fig 25. Schematic representation of the orientation of sliding planes and myocardial fibers in thick-walled and thinwalled ventricles. The mechanism hypothesized to allow for redistribution of fibers across the wall with decreasing LV volume is shown schematically by the blackened fibers. $N h$, Fiber count across wall; $h$, wall thickness; $N a$, fiber count per unit area. (From Spotnitz HM, Spotnitz WD, Cottrell TS, Spiro D, Sonnenblick EH. Cellular basis for volume related wall thickness changes in the rat left ventricle. J Mol Cell Cardiol 1974;6:317-31. Reprinted with permission of Academic Press, Ltd.)

In acute LV dilatation, radius increases and wall thickness decreases. A net decrease in the ratio of $\mathrm{r} / \mathrm{h}$ forces the myocardium to work harder than in the normal state to develop any given level of systolic pressure. ${ }^{18,19,67,68,71}$ The effect of changes in LV volume on the relation between wall stress and ventricular pressure is illustrated in Figs 35 and 36. The calculation of wall stress is relevant to afterload only and does not consider preload, contractility, or heart rate, which are also determinants of ventricular function. Although 


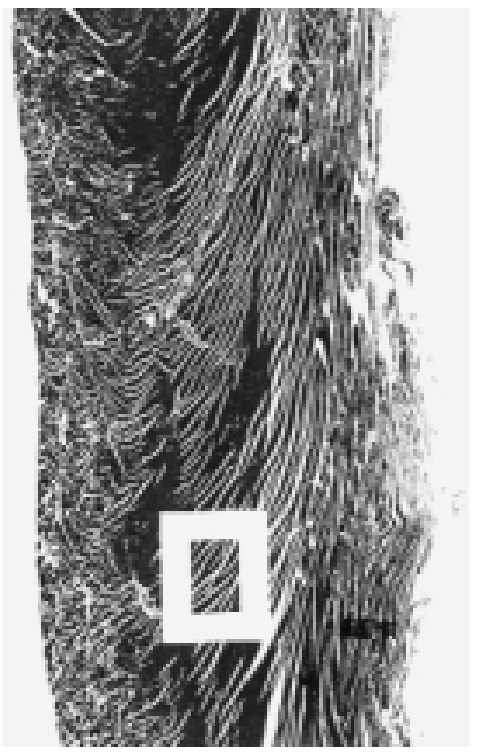

Fig 26. Similar to Fig 8: Longitudinal section of immature, fixed $\operatorname{dog} \mathrm{LV}$, low-power view. Cleavage planes contribute a characteristic pattern of spaces. (Spotnitz WD, Spotnitz HM, unpublished data.)

dilatation is problematic for LV pressure work, it is advantageous for volume work, since for any given stroke volume, ejection fraction decreases as end-diastolic volume increases. Furthermore, if ejection fraction remains constant, doubling end-diastolic volume will also double stroke volume.

With chronic volume loading, the ventricle undergoes plastic deformation, so that LV end-diastolic volume remains elevated above normal even if filling pressures are restored to normal levels. A second form of remodeling involves an increase in LV mass and synthesis of new structural elements and other components. This hypertrophy appears to be intended to restore a normal relation of $\mathrm{r} / \mathrm{h}$ in the dilated ventricle. This pattern is common in volume overloaded states and has been called "eccentric hypertrophy." ${ }^{3}$ The process of LV hypertrophy in volume overload counteracts the adverse effect of dilatation on pressure work by normalizing $\mathrm{r} / \mathrm{h} .{ }^{18,19,67,68,71}$ The concept of "afterload mismatch"18,19 envisions heart failure as caused by afterload that exceeds the maximum contractile force of the myocardium. This implies failure of hypertrophy to compensate for increased systolic loads.

In pressure overloaded states, an alternate form of hypertrophy increases wall thickness with little or no increase in radius. This "concentric hypertrophy" 63 allows normalization of wall stress despite high intraventricular pressures. However, the concept of wall stress is relevant to diastole as well as systole. The alternate form of the modified Laplace equation, $P=S$

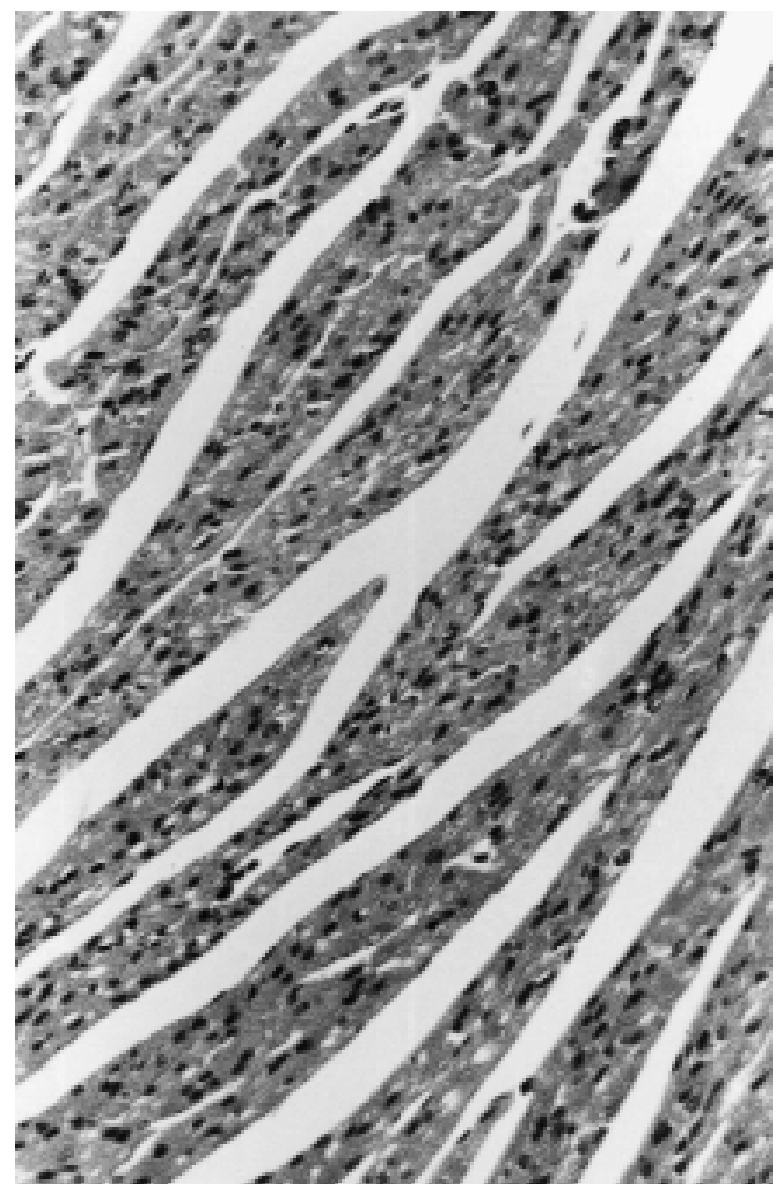

Fig 27. Similar to Fig 26: Longitudinal section of immature, fixed $\operatorname{dog} \mathrm{LV}$, high-power view.

$\times 2 h / r$, indicates that LV hypertrophy sufficient to double systolic pressure will also double LV end-diastolic pressure if diastolic wall stress is normal.

\section{Protein synthesis in the $\mathbf{L V}$}

The ability of the LV to remodel its functional architecture is striking. Signaling mechanisms in the cardiac myocyte respond to altered loads with accelerated protein synthesis in a matter of seconds. The uniformity of $r / h$ in hearts of different sizes from a variety of species, the maintenance of $\mathrm{r} / \mathrm{h}$ during eccentric hypertrophy, and the tendency of sarcomere length to normalize in the dilated heart all speak to the likelihood that mechanisms exist at the cellular level to sense and regulate wall stress. ${ }^{18,19,67,68,71}$ Protein synthesis is believed to renew the collagen matrix of the LV every 80 to 120 days. The turnover of contractile protein in the LV is much faster; myocardial contractile protein may be totally replaced every 12 days. ${ }^{38}$ 


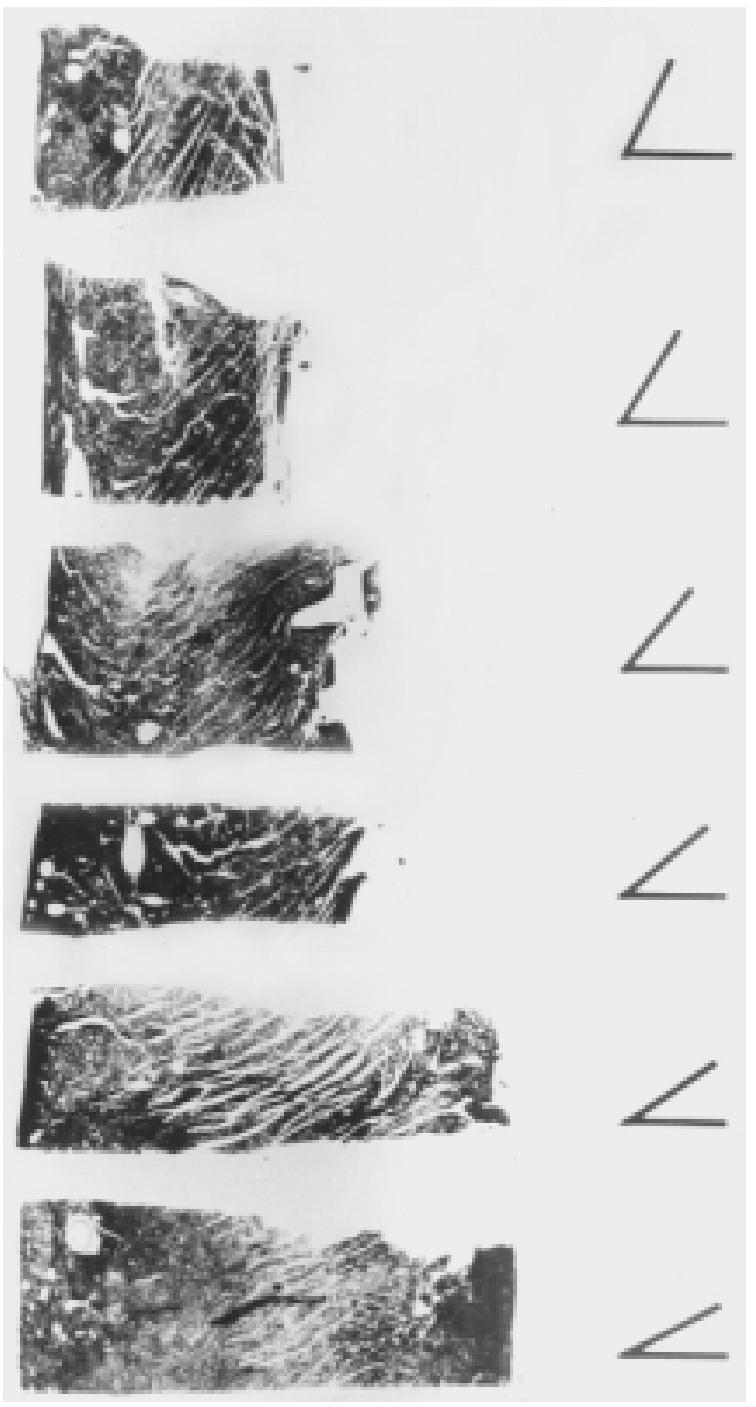

Fig 28. Longitudinal sections of fixed rat LVs. Intraventricular fixation pressure and volume increased from the bottom of the figure to the top, attenuating wall thickness. Entire thickness of the wall is shown, with epicardial surface to the left. Cleavage planes contribute a characteristic pattern of spaces to the sections processed with hematoxylin and eosin. The principal orientation of the planes changes with wall thickness in a way that would facilitate changes in thickness, as suggested in Fig 25. (From Spotnitz HM, Spotnitz WD, Cottrell TS, Spiro D, Sonnenblick EH. Cellular basis for volume related wall thickness changes in the rat left ventricle. J Mol Cell Cardiol 1974;6:317-31. Reprinted with permission of Academic Press, Ltd.)

\section{"Fiber slippage" and "creep"}

The idea of "slippage" or "creep" embodies the concept of plastic deformation of the collagen backbone of the $\mathrm{LV}$, with LV end-diastolic volume increased at any given end-diastolic pressure. ${ }^{47,48,72,73}$ An additional concept involves fiber rearrangement and increases in cell length, so that the relationship of sarcomere length to chamber volume is altered, and sarcomere length is shorter than expected in the chronically dilated LV (Fig 14). Thus diastolic myocardial sarcomere length in an experimental model of chronic LV volume overload was normal at midwall, about $2.2 \mu \mathrm{m}$, despite a $50 \%$ increase in LV volume resulting from an arteriovenous fistula. ${ }^{47}$ This observation implies an increase in the number of sarcomeres encircling the LV. One possible mechanism for this observation would involve synthesis of new sarcomeres in series within the cell and an increase in resting cell length ${ }^{74}$ (Fig 9). Alternatively, some form of "slippage," rearrangement of cells within the LV wall, or sarcomeres within the cell, might occur as a result of increased wall stress. Ultrastructural changes including loss of register of Z-lines of sarcomeres in adjacent myofibrils ${ }^{47}$ suggest distortion of individual cells. However, the counterpart of increasing ventricular volume at the cellular level remains obscure in many respects.

In experimental models of volume overload based on the aortocaval fistula, dilatation occurs slowly, over weeks. Both end-diastolic pressure and end-diastolic volume increase initially, followed by a decrease in end-diastolic pressure as the chamber dilates. ${ }^{49}$

Many issues related to structural changes in the LV wall during dilation due to volume overload also pertain to myocardial infarct expansion, in which changes in wall thickness have been related to changes in fiber counts and cleavage plane angles, with overstretched sarcomeres demonstrated in dilated regions of the wall. ${ }^{60,72,73}$

\section{Clinical controversies and issues related to dynamic $L V$ architecture}

Correction of volume overload. Surgical correction of volume overload acutely decreases LV end-diastolic pressure and volume, and dramatic recovery in structure and function of the LV may be observed over ensuing weeks. ${ }^{75-78}$ In the year after correction of mitral or aortic regurgitation, the majority of patients manifest a decrease in end-diastolic volume, $30 \%$ or more regression of LV hypertrophy, increasing LV ejection fraction, and improving indices of contractility. In some studies, LV dimensions have returned to normal. ${ }^{77,78}$ The time course of reversal of LV dilatation, which can occur in 6 weeks, is slower than the time course of reversal of hypertrophy, which requires 6 months or more and can continue for many years. The disproportionate reduction in LV enddiastolic volume can convert the eccentric hypertrophy of aortic insufficiency to a pattern resembling concentric hypertrophy. Morphologic studies have demonstrated decreasing LV myocyte size that parallels regression of 

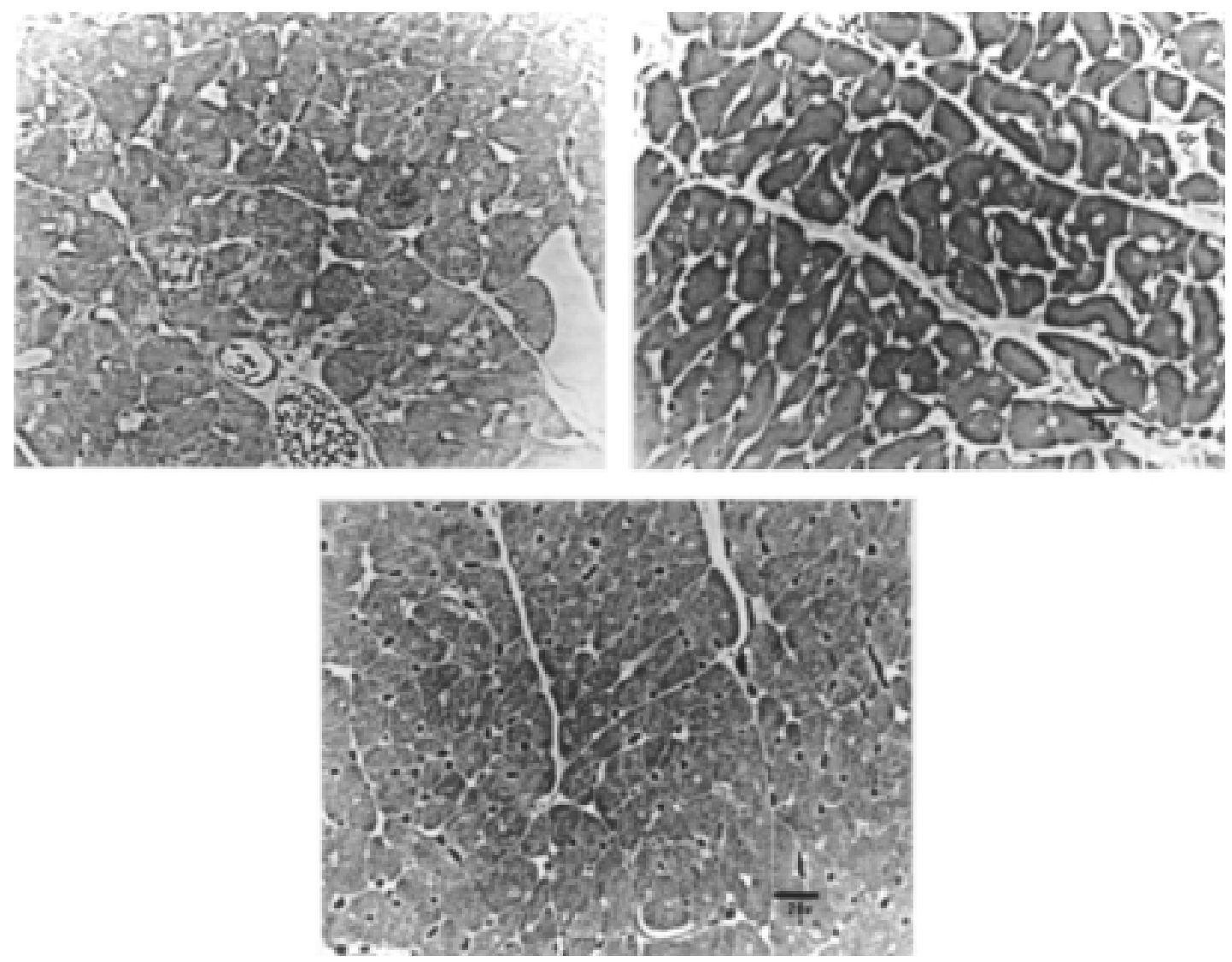

Fig 29. Cross section of circumferentially oriented fibers at midwall in the rat LV. Cross-fiber shortening would occur from left to right in this figure. Cellular boundaries are seen, which appear to be the sites of tissue separation when cleavage planes form during fixation. (From Spotnitz HM, Spotnitz WD, Cottrell TS, Spiro D, Sonnenblick EH. Cellular basis for volume related wall thickness changes in the rat left ventricle. J Mol Cell Cardiol 1974;6:317-31. Reprinted with permission of Academic Press, Ltd.)

hypertrophy. ${ }^{74,75}$ Myocardial fibrosis may decrease, but involution of myocardium results in a relative increase in fibrous tissue elements; this can cause an increase in myocardial stiffness. ${ }^{76}$ Problems with intraoperative myocardial protection may also be implicated in postoperative fibrosis.

The etiology of the gradual normalization of LV enddiastolic volume after reversal of volume overload is unknown. One canine model of mitral regurgitation has demonstrated increasing myocyte size and myofilament content after valve replacement for chronic mitral regurgitation, despite decreasing LV end-diastolic volume. ${ }^{74}$ Clinically, decreasing LV end-diastolic volume could reflect a gradual decrease in LV end-diastolic pressure as LV function improves. It is more likely that a true change in the LV diastolic pressure-volume curve occurs, with a shift toward normal. What the source of the restoring forces might be in such a process of "reverse creep"72 is not known. Scarring during regression of hypertrophy might generate restoring forces, but this has not been observed experimentally. ${ }^{74}$

Chronic mitral regurgitation is unique in its behavior. Valve surgery eliminates the low-resistance blowoff to the left atrium and may acutely decrease ejection fraction. In this lesion the LV is chronically myopathic, a condition partially masked by afterload reduction provided by the valve leak. ${ }^{29}$ It appears that the LV is particularly sensitive to small changes in loading in this condition, emphasizing the importance of any functional advantages achieved with valve repair.

LV aneurysmectomy. LV aneurysms form after large infarctions, commonly anteroseptal. LV aneurysm seems less common recently, as a result of improved therapy for acute myocardial infarction, including thrombolysis and percutaneous transluminal coronary 


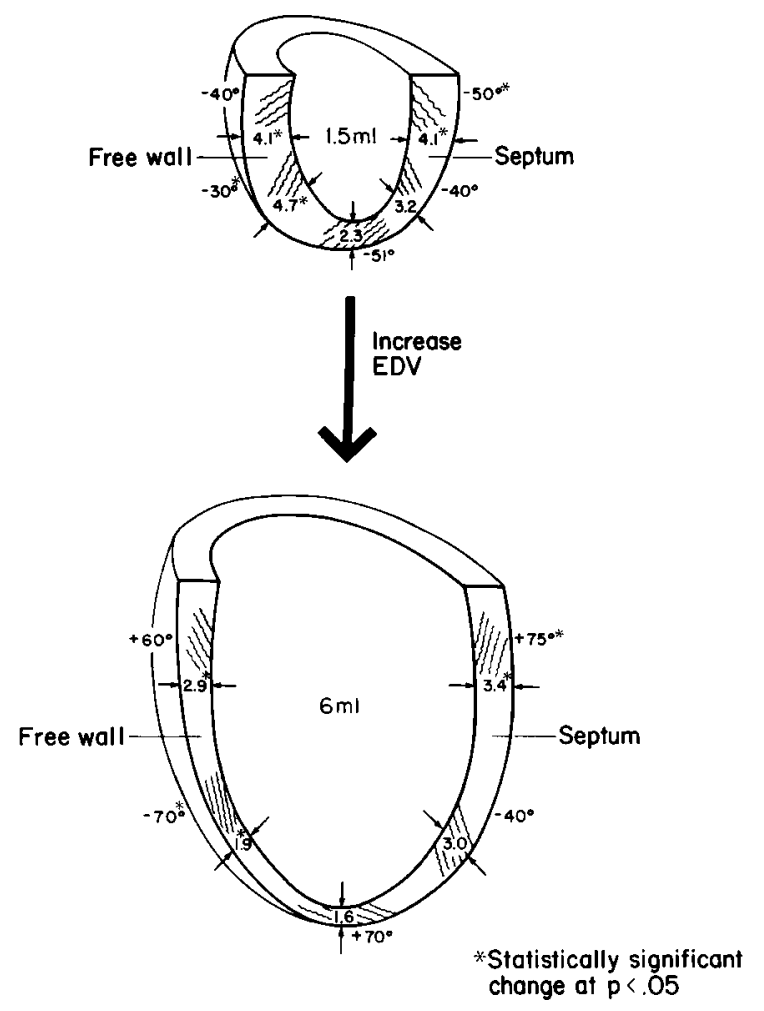

Fig 30. Effect of fixation volume on cleavage plane angle in five regions of the LV from immature dogs. An increase in average fixation volume from 1.5 to $6 \mathrm{~mL}$ was associated with statistically significant changes in cleavage plane angle at three of the five sites studied. The figure is drawn to scale to reflect changes in dimensions and cleavage plane angles.

angioplasty. Improved medical therapy of heart failure may also have decreased the urgency for surgical management of LV aneurysms. Pathophysiology of the mature lesion includes a large scar, as well as myopathic changes and coronary disease in remote myocardium. Favorable prognostic factors are functionally normal remote myocardium, minimal residual coronary disease, and a large, dyskinetic aneurysm. If the aneurysm is grossly dyskinetic, removing it improves global function and symptoms. When the aneurysm is really an akinetic scar and remote myocardium is functionally impaired, problems are common. ${ }^{27}$ Considerable speculation and study have been devoted to the issue of whether a scar in an impaired ventricle is best replaced by an akinetic patch or by bringing the edges of the myocardium together in a linear closure. ${ }^{27,28}$ Myocardial preservation, technical issues, and thrombogenic surface area aside, a number of geometric principles may be relevant (Fig. 20). First, larger ventricles

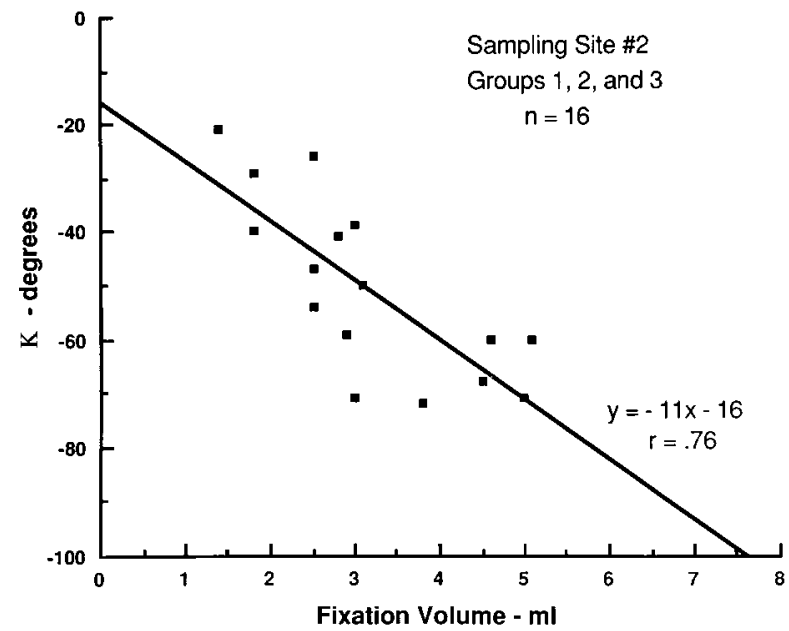

Fig 31. Relation between cleavage plane angle and fixation volume in one region of immature canine LV.

theoretically have bigger stroke volumes, even if the source of the size is an akinetic patch. Second, afterload increases with ventricular size, and this could lead to afterload mismatch. Third, marked geometric distortion with nonuniform stress distribution will cause regional dysfunction and should be avoided. The midwall circumferential fibers are most important, and their loading conditions should be kept as close to normal as possible. Clinical experience suggests that it is possible to make the remodeled LV too small as well as too large. At present, no formula or procedure exists that will predict the optimum operation for a given pathologic LV, and the clinician is left with clinical judgment and experience as the best guides to management of the individual case.

LV volume reduction. LV volume reduction surgery was proposed as a method of improving ventricular function in end-stage heart failure. ${ }^{31,32}$ The objective is to restore a normal mass/volume ratio, implying that this would reverse heart failure in patients having afterload mismatch. Although some patients report clinical improvement after LV volume reduction, it is not clear whether this reflects revision of ventricular mechanics or correction of mitral regurgitation by concomitant valvuloplasty. Since many patients are not improved by LV volume reduction, the theoretical underpinnings of the concept have been questioned ${ }^{57}$ (Fig 21). LV volume reduction can be distinguished from LV aneurysmectomy by the fact that the myocardium resected is not functionally different from what is left behind, by func- 


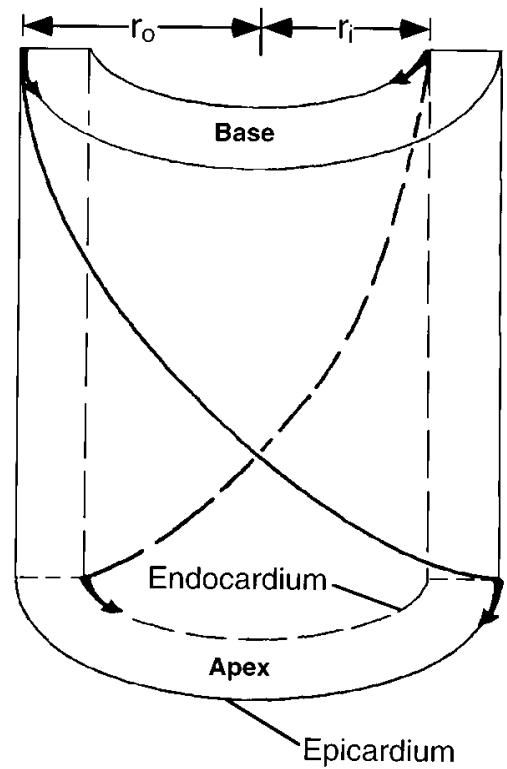

Fig 32. Model for generation of torque in the LV wall. Vectors for force generation at the epicardial and endocardial surfaces could neutralize each other. However, the epicardial fibers at the epicardial surface have a longer radius and a more powerful moment arm. In addition, sarcomere lengths, activation time, and infolding of the wall contribute to heterogeneity of the relation between structure and function between the inner and outer regions of the wall. Differences in the total force generated are believed responsible for LV systolic twist. $r_{o}$, Epicardial radius; $r_{i}$, endocardial radius. (Modified from Ingels NB Jr, Hansen DE, Daughters GT 2d, Stinson EB, Alderman EL, Miller DC. Relation between longitudinal, circumferential, and oblique shortening and torsional deformation in the left ventricle of the transplanted human heart. Circ Res 1989;64:915-27.)

tional symmetry of the failing LV, and by the absence of scarring, which allows larger changes in LV morphology than are possible after healing of a large myocardial infarction.

Until well-designed human or animal studies are carried out, the causes of failure of LV volume reduction in some patients remain undefined. However, the concept that restoration of a normal mass/volume relation and a normal relation of $\mathrm{r} / \mathrm{h}$ will create a functionally normal LV may prove simplistic. Normal $\mathrm{r} / \mathrm{h}$ is only one element in the optimally functioning LV, other relevant factors including preload, contractility, heart rate, and electrical activation sequence. Diastolic compliance is also important: if the remodeled chamber is stiff, optimal sarcomere length will require excessive filling pressure. ${ }^{57} \mathrm{LV}$ volume reduction also creates a

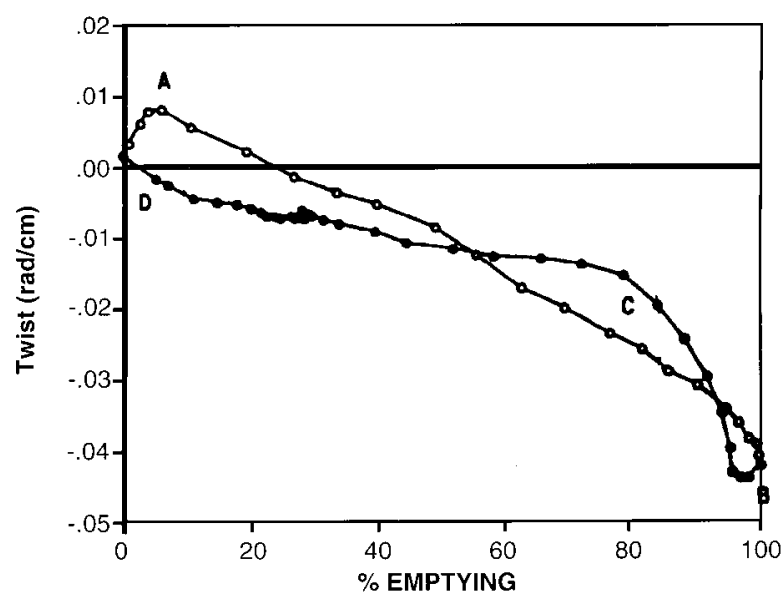

Fig 33. Wall twist during the cardiac cycle in human transplant recipient from fluoroscopy of surgically implanted tantalum markers. Systolic contraction from $A$ to $B$ is followed by rapid untwisting early in diastole from $B$ to $C$, consistent with elastic recoil. (Modified from Yun KL, Niczyporuk MA, Daughters GT 2d, Ingels NB Jr, Stinson EB, Alderman EL, et al. Alterations in left ventricular diastolic twist mechanics during acute human cardiac allograft rejection. Circulation 1991;83:962-73.)

long, noncompliant suture line and scar, the impact of which is unknown. Finally, intraoperative LV wall thickness can be pathologically altered by reactive hyperemia and edema, making the appearance of a "normal" $\mathrm{r} / \mathrm{h}$ difficult to interpret and of unknown functional significance. Studies of mitral regurgitation have revealed that morphology at the ventricular and cellular levels can give markedly different concepts of functional anatomy. ${ }^{74}$

Now that enthusiasm for LV volume reduction has subsided, the time may be right for carefully executed animal studies to define answers to many physiologic questions raised by this unique form of surgery. However, appropriate animal models of chronic, dilated heart failure with extensive, plastic deformation of ventricular architecture are essential for such studies, and this has been difficult to achieve.

Cardiomyoplasty. The use of skeletal muscle grafts to augment function of the failing $\mathrm{LV}$ is of considerable clinical and experimental interest. ${ }^{30}$ Although clinical benefits have been limited, further study in this area appears warranted. How to optimize the determinants of function in an artificial $\mathrm{LV}$ powered by skeletal muscle is interesting experimentally, particularly since many of the geometric factors involved can be independently controlled. 


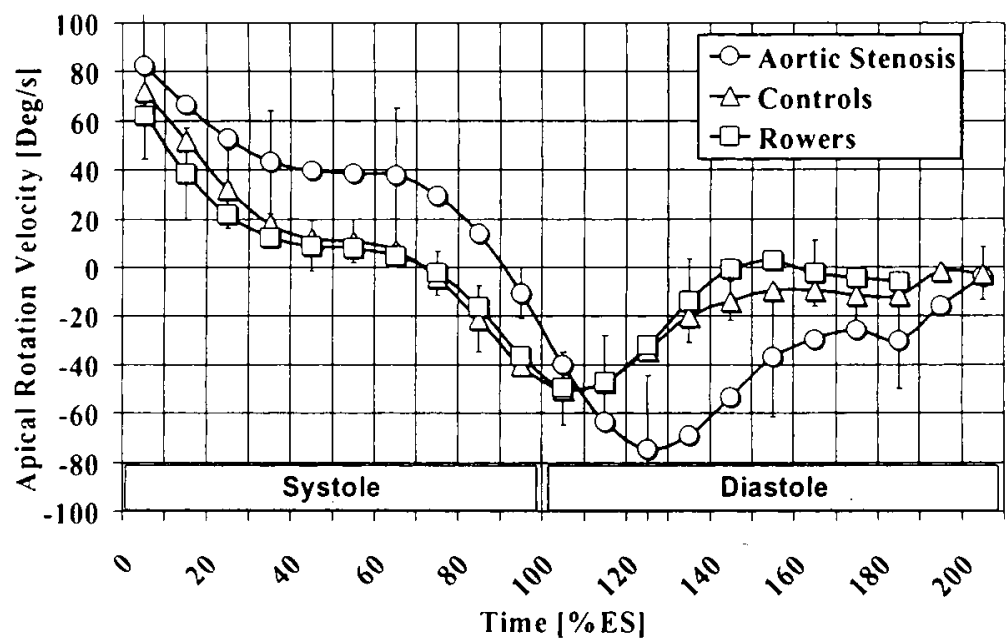

Fig 34. Similar to Fig 33, the average relation between apical rotation velocity and time is illustrated for the human LV in controls and groups with physiologic (rowers) and pathologic (aortic stenosis) hypertrophy. Data from NMR tagging show rapid changes in velocity in early and late systole and early diastole. Changes surrounding end-systole suggest storage and release of potential energy in elastic elements of the wall. (From Stuber M, Scheidegger MB, Fischer SE, Nagel E, Steinemann F, Hess OM, et al. Alterations in the local myocardial motion pattern in patients suffering from pressure overload due to aortic stenosis. Circulation 1999;100:361-8. Reprinted with permission of Lippincott Williams \& Wilkins.)

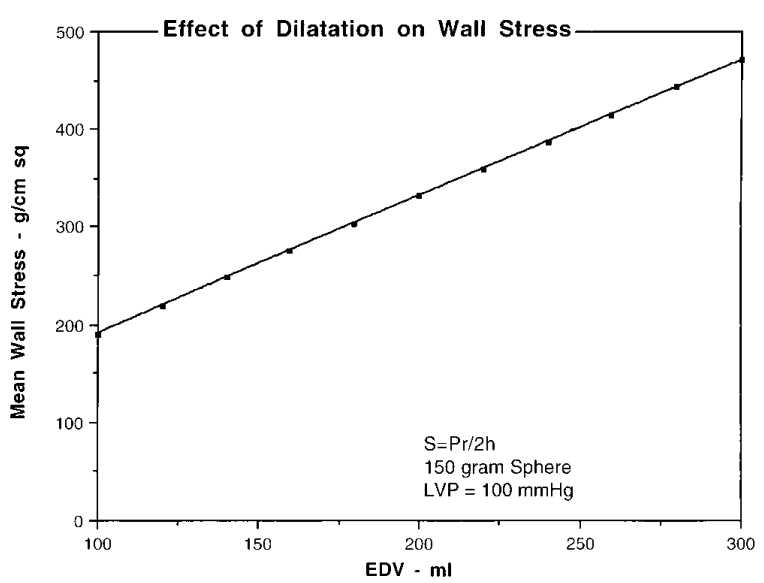

Fig 35. Effect of chamber dilatation on wall stress (afterload) if $L V$ systolic pressure $(L V P)$ remains constant calculated for a 150 -g sphere. Increasing LV end-diastolic volume $(E D V)$ increases the afterload imposed on the muscle fibers and may affect sarcomere shortening ("afterload mismatch") unless muscle force increases. The effect is neutralized if hypertrophy maintains normal radius-wall thickness ratio. Preload (sarcomere length) and contractility are assumed constant. (From Spotnitz HM, Antunes ML. Effect of aortic and mitral regurgitation on left ventricular structure and function. Adv Card Surg 1991;2:85-116. Reprinted with permission of Mosby, Inc.)

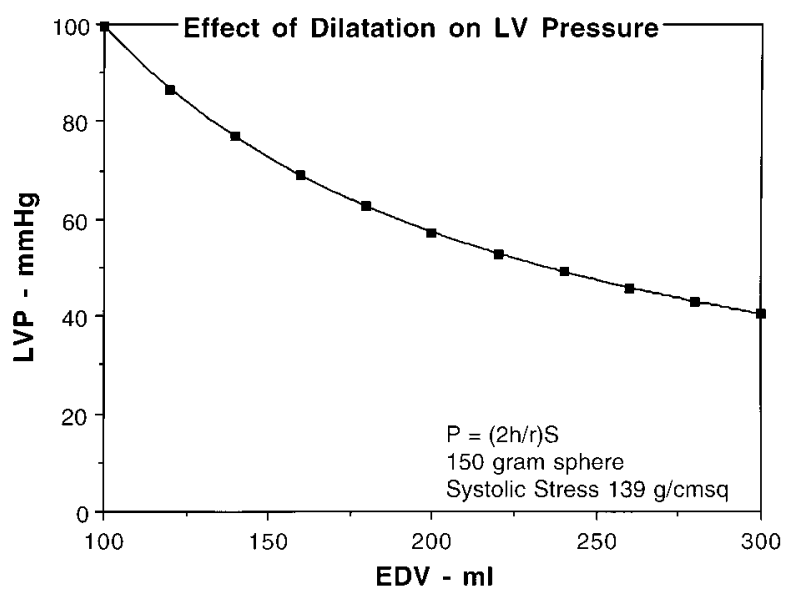

Fig 36. Detrimental effect of geometry of chamber dilatation on the systolic pressure-afterload (wall stress) relation. Data are calculated for a 150-g sphere. At a constant systolic force of contraction, dilatation reduces peak LV systolic pressure $(L V P)$. Effects of changes in sarcomere length (preload) or contractility are not considered. $E D V$, End-diastolic volume. (From Spotnitz HM, Antunes ML. Effect of aortic and mitral regurgitation on left ventricular structure and function. Adv Card Surg 1991;2:85-116. Reprinted with permission of Mosby, Inc.) 


\section{Summary}

The LV is a remarkable product of natural engineering, characterized by the unique ability to translate $15 \%$ linear sarcomere shortening into ejection fractions of greater than $50 \%$ and wall thickening greater than $30 \%$. There is still much to learn about how this is accomplished. Ideally, what is learned will contribute to advances in our understanding of pathophysiology and to our ability to help this incredible engine do its daily work.

The excellent editorial assistance of Ms May Deutsch is gratefully acknowledged.

\section{REFERENCES}

1. Greenbaum RA, Ho SY, Gibson DG, Becker AE, Anderson RH. Left ventricular fibre architecture in man. Br Heart $\mathrm{J}$ 1981;45:248-63.

2. Streeter DD Jr, Spotnitz HM, Patel DP, Ross J Jr, Sonnenblick EH. Fiber orientation in the canine left ventricle during systole and diastole. Circ Res 1969;24:339-47.

3. Spotnitz HM, Spotnitz WD, Cottrell TS, Spiro D, Sonnenblick EH. Cellular basis for volume related wall thickness changes in the rat left ventricle. J Mol Cell Cardiol 1974;6:317-31.

4. Spotnitz HM, Sonnenblick EH, Spiro D. Relation of ultrastructure to function in the intact heart: sarcomere structure relative to pressure volume curves of intact left ventricles of the dog and cat. Circ Res 1966;18:49-66.

5. Sonnenblick EH, Ross J Jr, Covell JW, Spotnitz HM, Spiro D. Ultrastructure of the heart in systole and diastole: changes in sarcomere length. Circ Res 1967;21:424-36.

6. Mitchell JH, Wildenthal K, Mullins CB. Geometric studies of the left ventricle utilizing biplane cinefluorography. Fed Proc 1969;28:1334-43.

7. Sandler H, Dodge HT. Left ventricular tension and stress in man. Circ Res 1963;13:91-104.

8. Haasler GB, Rodigas PC, Collins RH, Wei J, Meyer FJ, Spotnitz AJ, et al. Two-dimensional echocardiography in dogs: variation of left ventricular mass, geometry, volume, and ejection fraction on cardiopulmonary bypass. J Thorac Cardiovasc Surg 1985;90:430-40.

9. Eaton LW, Maughan WL, Shoukas AA, Weiss JL. Accurate volume determination in the isolated ejecting canine left ventricle by two-dimensional echocardiography. Circulation 1979;60:320-6.

10. Stuber M, Scheidegger MB, Fischer SE, Nagel E, Steinemann F, Hess OM, et al. Alterations in the local myocardial motion pattern in patients suffering from pressure overload due to aortic stenosis. Circulation 1999;100:361-8.

11. Lima JA, Jeremy R, Guier W, Bouton S, Zerhouni EA, McVeigh $\mathrm{E}$, et al. Accurate systolic wall thickening by nuclear magnetic resonance imaging with tissue tagging: correlation with sonomicrometers in normal and ischemic myocardium. J Am Coll Cardiol 1993;21:1741-51.

12. Ingels NB, Daughters GT 2d, Stinson EB, Alderman EL. Measurement of midwall myocardial dynamics in man by radiography of surgically implanted markers. Circulation 1975;52:859-67.
13. Ingels NB Jr, Hansen DE, Daughters GT 2d, Stinson EB, Alderman EL, Miller DC. Relation between longitudinal, circumferential, and oblique shortening and torsional deformation in the left ventricle of the transplanted human heart. Circ Res 1989;64:915-27.

14. Rankin JS, McHale PA, Arentzen CE, Ling D, Greenfield JC Jr, Anderson RW. The three-dimensional dynamic geometry of the left ventricle in the conscious dog. Circ Res 1976;39:304-13.

15. Olsen CO, Rankin JS, Arentzen CE, Ring WS, McHale PA, Anderson RW. The deformational characteristics of the left ventricle in the conscious dog. Circ Res 1981;49:843-55.

16. Ross J Jr, Sonnenblick EH, Covell JW, Kaiser G, Spiro D. The architecture of the heart in systole and diastole: technique of rapid fixation and analysis of left ventricular geometry. Circ Res 1967;21:409-21

17. Troy BL, Pombo JF, Rackley CE. Ultrasonic measurements of left ventricular wall thickness in man. Circulation 1970;42(Suppl):III-38.

18. Gaasch WH, Carroll JD, Levine JH, Criscitiello MG. Chronic aortic regurgitation: prognostic value of left ventricular end-systolic dimension and end-diastolic radius/thickness ratio. J Am Coll Cardiol 1983;1:775-82.

19. Ross J Jr. Afterload mismatch in aortic and mitral disease: implications for surgical therapy. J Am Coll Cardiol 1985;5:811-26.

20. Schuler G, Peterson KL, Johnson A, Francis G, Dennish G, Utley $\mathrm{J}$, et al. Temporal response of left ventricular performance to mitral valve surgery. Circulation 1979;59:1218-31.

21. Lillehei CW, Levy MJ, Bonnabeau RC. Mitral valve replacement with preservation of the papillary muscles and the chordae tendineae. J Thorac Cardiovasc Surg 1964;47:532-43.

22. Carpentier A. Cardiac valve surgery-the French correction. J Thorac Cardiovasc Surg 1983;86:323-36.

23. David TE, Burns RJ, Bacchus CM, Druck MN. Mitral valve replacement for mitral regurgitation with and without preservation of chordae tendineae. J Thorac Cardiovasc Surg 1984;88:718-25.

24. Salter DR, Pellom GL, Murphy CE, Brunsting LA, Goldstein JP, Morris JM 3d, et al. Papillary annular continuity and left ventricular systolic function after mitral valve replacement. Circulation 1986;74(Suppl):I-121-9.

25. Sarris GE, Cahill PD, Hansen DE, Derby GC, Miller DC. Restoration of left ventricular systolic performance after reattachment of the mitral chordae tendineae: the importance of valvular-ventricular interaction. J Thorac Cardiovasc Surg 1988;95:969-79

26. Sarris GE, Miller DC. Valvular-ventricular interaction: the importance of the mitral chordae tendineae in terms of global left ventricular systolic function. J Card Surg 1988;3:215-34.

27. Jatene A. Left ventricular aneurysmectomy: resection or reconstruction. J Thorac Cardiovasc Surg 1985;89:321-31.

28. Nicolosi AC, Weng Z-C, Detwiler PW, Spotnitz HM. Simulated left ventricular aneurysm and aneurysm repair in swine. J Thorac Cardiovasc Surg 1990;100:745-55.

29. Spotnitz HM, Antunes ML. Effect of aortic and mitral regurgitation on left ventricular structure and function. Adv Card Surg 1991;2:85-116.

30. Acker MA. Dynamic cardiomyoplasty: at the crossroads. Ann Thorac Surg 1999;68:750-5.

31. Batista RJV, Santos JLV, Takeshita N, Bocchino L, Lima PN, Cunha MA. Partial left ventriculectomy to improve left ventricular function in end-stage heart disease. J Card Surg 1996;11:96-7. 
32. Laks H, Marelli D. The current role of left ventricular reduction for the treatment of heart failure. J Am Coll Cardiol 1998;32:1809-10.

33. Guccione JM, O'Dell WD, McCulloch AD, Hunter WC. Anterior and posterior left ventricular sarcomere lengths behave similarly during ejection. Am J Physiol 1997;272:H469-77.

34. Ahmad RM, Spotnitz HM. Computer visualization of left ventricular geometry during the cardiac cycle. Comput Biomed Res 1992;25:201-11.

35. Badeer HS. Contractile tension in the myocardium. Am Heart $\mathbf{J}$ 1963;66:432-7.

36. Streeter DD Jr, Vaishnav RN, Patel DJ, Spotnitz HM, Ross J Jr, Sonnenblick EH. Stress distribution in the canine left ventricle during diastole and systole. Biophys J 1970;10:343-63.

37. Spotnitz HM, Cabreriza SE, Hart JP. Intraoperative echocardiography: interpretation of changes in left ventricular wall thickness. Semin Thorac Cardiovasc Surg 1998;10:273-83.

38. Weber K. Cardiac interstitium in health and disease: the fibrillar collagen network. J Am Coll Cardiol 1989;7:1637-52.

39. May-Newman K, Mathieu-Costello O, Omens JH, Klumb K, McCulloch AD. Transmural distribution of capillary morphology as a function of coronary perfusion pressure in the resting canine heart. Microvasc Res 1995;50:381-96.

40. Bishop SP, Drummond JL. Surface morphology and cell size measurement of isolated rat cardiac myocytes. J Mol Cell Cardiol 1979;11:423-33.

41. Allen DG, Kentish JC. The cellular basis of the length-tension relation in cardiac muscle. J Mol Cell Cardiol 1985;17:821-40.

42. Pollack GH. The crossbridge theory. Physiol Rev 1983;63:1049113.

43. Richter GW, Kellner A. Hypertrophy of the human heart at the level of fine structure. J Cell Biol 1963;18:195-206.

44. Trombitas K, Granzier H. Actin removal from cardiac myocytes shows that near $\mathrm{Z}$ line titin attaches to actin while under tension. Am J Physiol 1997;273:C662-70.

45. Spotnitz WD, Spotnitz HM, Truccone NJ, Cottrell TS, Gersony W, Malm JR, et al. Relation of ultrastructure to function: sarcomere dimensions, pressure volume curves, and geometry of the intact left ventricle of the immature canine heart. Circ Res 1979;44:679-91.

46. Taylor TW, Goto Y, Suga H. On the solutions of Huxley-type models in cardiac muscle fiber contractions. J Theor Biol 1993; 165:409-16.

47. Ross J Jr, Sonnenblick EH, Taylor RR, Spotnitz HM, Covell JW. Diastolic geometry and sarcomere lengths in the chronically dilated canine left ventricle. Circ Res 1971;28:49-61.

48. Downing SW, Savage EB, Streicher JS, Bogen DK, Tyson GS, Edmunds LH Jr. The stretched ventricle: myocardial creep and contractile dysfunction after acute nonischemic ventricular distention. J Thorac Cardiovasc Surg 1992;104:996-1005.

49. McCullagh WH, Covell JW, Ross J Jr. Left ventricular dilatation and diastolic compliance changes during chronic volume overloading. Circulation 1972;45:943-51.

50. Grimm AF. Editorial: myocardial sarcomeres and the functioning mammalian heart. Basic Res Cardiol 1976;71:113-8.

51. Gordon AM, Pollack GH. Effects of calcium on the sarcomere length-tension relation in rat cardiac muscle: Implications for the Frank-Starling mechanism. Circ Res 1980;47:610-9.

52. Roos KP, Brady AJ. Individual sarcomere length determination from isolated cardiac cells using high-resolution optical microscopy and digital image processing. Biophys $\mathrm{J}$ 1982;40:233-44.
53. Rodriguez EK, Omens JH, Waldman LK, McCulloch AD. Effect of residual stress on transmural sarcomere length distributions in rat left ventricle. Am J Physiol 1993;264:H1048-56.

54. Spotnitz HM, Sonnenblick EH. Structural conditions in the hypertrophied and failing heart. In: Mason DT, editor. Congestive heart failure. New York: Yorke Medical Books; 1976. p. 13-24.

55. Kass DA, Traill TA, Keating M, Altieri PI, Maughan WL. Abnormalities of dynamic ventricular shape change in patients with aortic and mitral valvular regurgitation: assessment by Fourier shape analysis and global geometric indexes. Circ Res 1988;62:127-38.

56. Rademakers FE, Rogers WJ, Guier WH, Hutchins GM, Siu CO, Weisfeldt ML, et al. Relation of regional cross-fiber shortening to wall thickening in the intact heart: three-dimensional strain analysis by NMR tagging. Circulation 1994;89:1174-82.

57. Dickstein ML, Spotnitz HM, Rose EA, Burkhoff D. Heart reduction surgery: an analysis of the impact on cardiac function. $\mathrm{J}$ Thorac Cardiovasc Surg 1997;113:1032-40.

58. Dean DA, Amirhamzeh MMR, Jia C-X, Cabreriza SE, Rabkin DG, Sciacca R, et al. Reversal of iatrogenic myocardial edema and related abnormalities of diastolic properties in the pig left ventricle. J Thorac Cardiovasc Surg 1998;115:1209-14.

59. Rackley CE, Hood WP Jr, Grossman W. Measurements of ventricular volume, mass, and ejection fraction. In: Grossman W, editor. Cardiac catheterization and angiography, ed 2 . Philadelphia: Lea \& Febiger; 1980. p 232-44.

60. Weisman HF, Bush DE, Mannisi JA, Weisfeldt ML, Healy B. Cellular mechanisms of myocardial infarct expansion. Circulation 1988;78:186-201.

61. Costa KD, Takayama Y, McCulloch AD, Covell JW. Laminar fiber architecture and three-dimensional systolic mechanics in canine ventricular myocardium. Am J Physiol 1999;276:H595-607.

62. Spotnitz WD, Wolff M, Spotnitz HM. Volume-related alterations of cleavage plane angles in the left ventricular wall [abstract]. Circulation 1982;66(Suppl):II-252.

63. Linzbach AJ. Heart failure from the point of view of quantitative anatomy. Am J Cardiol 1960;5:370-82.

64. Yun KL, Niczyporuk MA, Daughters GT 2d, Ingels NB Jr, Stinson EB, Alderman EL, et al. Alterations in left ventricular diastolic twist mechanics during acute human cardiac allograft rejection. Circulation 1991;83:962-73.

65. Ormiston JA, Shah PM, Tei C, Wong M. Size and motion of the mitral valve annulus in man. I. A two-dimensional echocardiographic method and findings in normal subjects. Circulation 1981;64:11-120.

66. Ingels NB Jr, Daughters GT 2d, Stinson EB, Alderman EL, Miller DC. Three-dimensional left ventricular midwall dynamics in the transplanted human heart. Circulation 1990;81:1837-48.

67. Falsetti HL, Mates RE, Grant C, Greene DG, Bunnell IL. Left ventricular wall stress calculated from one-plane cineangiography: an approach to force-velocity analysis in man. Circ Res 1970;26:71-83.

68. Hood WP Jr, Thomson WJ, Rackley CE, Rolett EL. Comparison of calculations of left ventricular wall stress in man from thinwalled and thick-walled ellipsoidal models. Circ Res 1969;24:575-82.

69. Mirsky I. Left ventricular stresses in the intact human heart. Biophys J 1969;9:189-208.

70. Wong AYK, Rautaharju PM. Stress distribution within the left ventricular wall approximated as a thick ellipsoidal shell. Am Heart J 1968;75:649-62.

71. Grossman W, Jones D, McLaurin LP. Wall stress and patterns of hypertrophy in the human left ventricle. J Clin Invest 1975;56:56-64. 
72. Glower DD, Schaper J, Kabas JS, Hoffmeister HM, Schaper W, Spratt JA, et al. Relation between reversal of diastolic creep and recovery of systolic function after ischemic myocardial injury in conscious dogs. Circ Res 1987;60:850-60.

73. Olivetti G, Capasso JM, Sonnenblick EH, Anversa P. Side-to-side slippage of myocytes participates in ventricular wall remodeling acutely after myocardial infarction in rats. Circ Res 1990;67:23-34.

74. Spinale FG, Ishihra K, Zile M, DeFryte G, Crawford FA, Carabello BA. Structural basis for changes in left ventricular function and geometry because of chronic mitral regurgitation and after correction of volume overload. J Thorac Cardiovasc Surg 1993;106:1147-57.

75. Krayenbuehl HP, Hess OM, Monrad ES, Schneider J, Mall G, Turina M. Left ventricular myocardial structure in aortic valve disease before, intermediate, and late after aortic valve replacement. Circulation 1989;79:744-55.
76. Hess OM, Ritter M, Schneider J, Grimm J, Turina M, Krayenbuehl HP. Diastolic stiffness and myocardial structure in aortic valve disease before and after valve replacement. Circulation 1984;69:855-65.

77. Monrad ES, Hess OM, Murakami T, Nonogi H, Corin WJ, Krayenbuehl HP. Time course of regression of left ventricular hypertrophy after aortic valve replacement. Circulation 1988;77:1345-55.

78. Roman MJ, Klein L, Devereux RB, Kligfield P, Niles NW, Hochreiter C, et al. Reversal of left ventricular dilatation, hypertrophy, and dysfunction by valve replacement in aortic regurgitation. Am Heart J 1989;118:553-63.

79. Sonnenblick EH, Spiro D, Cottrell TS. Fine structural changes in heart muscle in relation to the length tension curve. Proc Natl Acad Sci U S A 1963;49:193-200. 